\title{
Tungsten-Niobium Oxide Bronzes: A Bulk and Surface \\ Structural Study
}

by

Daniel Delgado a,b, ${ }^{,}$, Patricia Concepción ${ }^{\mathrm{a}}$, Annette Trunschke ${ }^{\mathrm{b}}$ and Jose M.

López Nietoa,

a) Instituto de Tecnología Química, Universitat Politècnica de València-Consejo

Superior de Investigaciones Científicas, Avenida de los Naranjos s/n, 46022

Valencia, Spain. E-mail: jmlopez@itq.upv.es; dadelmuo@gmail.com

b) Department of Inorganic Chemistry, Fritz-Haber-Institute of the Max-PlanckGesellschaft, 14195 Berlin, Germany.

*) Corresponding authors: jmlopez@itq.upv.es; dadelmuo@gmail.com

ORCID

Daniel Delgado: 0000-0002-2976-3322

Jose M. López Nieto: 0000-0002-6960-3219 


\section{Abstract}

Materials from $\mathrm{WO}_{3}-\mathrm{Nb}_{2} \mathrm{O}_{5}$ system, presenting bronze-type crystal structures, display outstanding functional properties for several applications, like thermoelectric materials, lithium-ion battery electrodes, or as catalysts. In this work a series of $\mathrm{W}-\mathrm{Nb}-\mathrm{O}$ oxide bronzes has been synthesized by the hydrothermal method (with $\mathrm{Nb} /(\mathrm{W}+\mathrm{Nb})$ ratios in the range $0-1)$. A combination of bulk and surface characterisation techniques has been applied to get further insights on: i) the effect of thermal treatments on as-prepared materials; and ii) the surface chemical nature of $\mathrm{W}-\mathrm{Nb}-\mathrm{O}$ oxide bronzes. Thermal treatments promote the following structural changes: i) loss of emerging long-range order and; ii) the elimination of $\mathrm{NH}_{4}{ }^{+}$and $\mathrm{H}_{2} \mathrm{O}$ species from the structural channels of the as-synthesized materials. It has been observed that $\mathrm{W}-\mathrm{Nb}-\mathrm{O}$ bronzes with $\mathrm{Nb}$ at. $\%$ of ca. $50 \%$ are able to retain long-range order after heat-treatments, what is related with the presence of $\mathrm{Cs}_{0.5}\left[\mathrm{~W}_{2.5} \mathrm{Nb}_{2.5} \mathrm{O}_{14}\right]$-type structure. Increasing amounts of $\mathrm{Nb}^{5+}$ in the materials: i) promote a phase transition to pseudocrystalline phases ordered along c-axis; ii) stabilize surface $\mathrm{W}^{5+}$ species (elucidated by XPS); and, iii) increase the proportion of surface Lewis acid sites (as determined by FTIR of adsorbed CO). Results suggest that pseudocrystalline oxides (with a $\mathrm{Nb}$ at. $\% \geq 50 \%$ ) are closely related with $\mathrm{NbO}_{7}$ pentagonal bipyramids-containing structures. The stabilisation of Lewis acid sites on these pseudocrystalline materials leads to a higher yield to heavy compounds, at the expense of acrolein formation, in the gas-phase dehydration of glycerol.

Keywords: 


\section{Introduction}

Metal oxides with bronze-type structures can be considered one of the most versatile families of materials in terms of functional properties and applications. Their wide applicability derives in part from their adaptive compositional features, but also from their defect-rich chemistry. ${ }^{1,2}$

Metal oxide bronzes are usually defined as partially reduced transition metal oxide phases, in which constituent elements incorporated within the crystal framework (generally $\mathrm{W}, \mathrm{Mo}, \mathrm{V}, \mathrm{Nb}, \mathrm{Ta}, \mathrm{Ti}$ or $\mathrm{U}$ ) present a mixed oxidation state. ${ }^{1}$ This mixture of oxidation states can be stabilized either by the incorporation of electropositive species (like alkaline-earth metals, or ammonium ions), generally inside of 5-8 membered channels of the structure (i.e. intercalation compounds) ${ }^{3}$ or by the generation of structural defects (like in the case of block structures in niobium oxide system, ${ }^{4,5}$ or Magneli phases in tungsten oxides ${ }^{6,7}$ ).

Among them, tungsten oxide bronzes are one of the most studied systems. Perovskite, hexagonal (HTB) or tetragonal (TTB) tungsten oxide bronzes have found applications in a vast numbers of research fields, such as superconductors, ${ }^{8}$ capacitors, ${ }^{9}$ catalysis, ${ }^{10-13}$ magnetic ${ }^{14}$ or optical materials. ${ }^{15,16}$ In all cases, the possibility to achieve such diverse functionalities comes from their ability to admit a great variety of elements within their crystal lattice, from most of the groups of the periodic table, like rare earths, ${ }^{17,18}$ transition metals $^{1}$ or semimetals. ${ }^{19}$

In the present study, we have focused our attention on the $\mathrm{WO}_{3}-\mathrm{Nb}_{2} \mathrm{O}_{5}$ system. In particular, novel applications for $\mathrm{W}-\mathrm{Nb}-\mathrm{O}$ bronze type oxides have recently emerged. For instance, mixed $\mathrm{W}-\mathrm{Nb}-\mathrm{O}$ oxides with a TTB structure have shown 
thermoelectric properties, ${ }^{20}$ and also outstanding rates for lithium-ion diffusion and high storage capacity. ${ }^{21}$ This system also displays interesting catalytic properties in the transformation of biomass-derived feedstocks, ${ }^{11-13,22,23}$ presenting high activity and selectivity, and also good stability under highly demanding reaction conditions, like very low $\mathrm{pH}$ and aqueous environments. ${ }^{23}$

Despite their wide applications in materials science, studies on their formation mechanisms under mild conditions (like hydrothermal or reflux methods) ${ }^{24,25}$ and on their surface chemistry, as well as those dedicated to study activation processes, are scarce. This derives from the more extended synthesis protocols applied, which are based on high temperatures heat treatments (above $1000^{\circ} \mathrm{C}$ ) under controlled atmospheres. These synthetic procedures are suitable for most of their practical uses. However, for applications in catalysis, soft synthesis methods are required. Hydrothermal, ${ }^{11-13,26-29}$ reflux $^{30,31}$ or slurry ${ }^{32}$ methodologies are the most common ones, not only for the synthesis of tungsten-bronze based materials, but also for the preparation of other bronze-type oxides based on molybdenum or vanadium. ${ }^{33-35}$ Unlike methods based on solid state reactions, these mild synthesis protocols allow to achieve active surface areas large enough to carry out catalytic reactions.

Herein we report the structural and chemical evolution of $\mathrm{W}-\mathrm{Nb}-\mathrm{O}$ oxides, presenting bronze-type structures, during their thermal activation. The materials were prepared by hydrothermal synthesis and subsequently heat-treated at different temperatures in $\mathrm{N}_{2}$ flow. Surface features of heat-treated $\mathrm{W}-\mathrm{Nb}-\mathrm{O}$ oxide bronzes are discussed and linked with both their particular structural characteristics and their catalytic performance in the gas-phase dehydration of glycerol. 


\section{Experimental}

\section{Synthesis}

A series of $\mathrm{W}-\mathrm{Nb}-\mathrm{O}$ oxides, with $\mathrm{Nb}$ at. \% ratios in the range $0-100$, have been synthesized by the hydrothermal method, using ammonium metatungstate hydrate ( $\geq 85$ wt. $\% \mathrm{WO}_{3}$ basis, Sigma-Aldrich) and niobium oxalate (monooxalate adduct, $A B C R$ ) as precursors. Acidified aqueous solutions containing stoichiometric amounts of the corresponding metal salts $\left(\mathrm{pH}=1, \mathrm{H}_{2} \mathrm{O}:(\mathrm{W}+\mathrm{Nb})\right.$ molar ratio 53:1) were introduced into Teflon-lined stainless steel autoclaves, and subsequently purged with $\mathrm{N}_{2}$. Autoclaves were then heated at $175^{\circ} \mathrm{C}$ for $48 \mathrm{~h}$. The resulting solids were filtered, washed with distilled water, and dried at $100^{\circ} \mathrm{C}$ for $16 \mathrm{~h}$. Finally, dried as-prepared solids were heat-treated at $550{ }^{\circ} \mathrm{C}$ or $800^{\circ} \mathrm{C}$ under $\mathrm{N}_{2}$ flow (15 mL min-1 $\left.\mathrm{gcat}^{-1}\right)$. Nb-containing catalysts are named WNby, being $\boldsymbol{y}$ the bulk $\mathrm{Nb}$ at. \% measured by XEDS. Table 1 shows some characteristics of samples heat-treated at $550^{\circ} \mathrm{C}$.

Pure Niobium oxide, heat-treated at $550{ }^{\circ} \mathrm{C}$, was named as $\mathrm{Nb} 100$. For comparison, pure tungsten oxide, denoted as WOx, was heat-treated at $450{ }^{\circ} \mathrm{C}$ in order to avoid the phase transition from the hexagonal tungsten bronze structure $\left(h-\mathrm{WO}_{3}\right)$ to the monoclinic tungsten oxide phase $\left(m-\mathrm{WO}_{3}\right) .{ }^{11}$ 
Table 1. Characteristics of $\mathrm{W}-\mathrm{Nb}-\mathrm{O}$ oxide bronzes heat-treated at $550^{\circ} \mathrm{C}$.

\begin{tabular}{llllll}
\hline Sample & \multicolumn{2}{l}{$\mathbf{N b} /(\mathbf{W}+\mathbf{N b})$} & $\mathbf{W}^{5+} /\left(\mathbf{W}^{6+}+\mathbf{W}^{5+}\right)$ & \multicolumn{2}{c}{ Surface Oxygen $(\mathbf{a t .} \%)^{b}$} \\
\cline { 2 - 3 } \cline { 5 - 6 } & Bulk $^{a}$ & Surface $^{b}$ & & Lattice & Defects \\
\hline WOx & 0.00 & 0.00 & 0.14 & 92.5 & 7.5 \\
WNb29 & 0.29 & 0.23 & 0.05 & 74.1 & 25.1 \\
WNb62 & 0.62 & 0.55 & 0.18 & 83.7 & 16.3 \\
WNb80 & 0.80 & 0.70 & 0.22 & 84.5 & 15.5 \\
WNb95 & 0.95 & 0.84 & 0.34 & 67.9 & 32.1 \\
Nb100 & 1.00 & 1.00 & 0.00 & 76.7 & 23.3 \\
\hline
\end{tabular}

a) Determined by Energy Dispersive X-ray Spectroscopy (XEDS).

b) Determined by XPS.

\section{Characterisation of materials}

The bulk chemical composition of $\mathrm{W}-\mathrm{Nb}-\mathrm{O}$ oxides was measured by Energy Dispersive X-ray Spectroscopy (XEDS) in a JEOL 6300 scanning electron microscope equipped with an Oxford LINK ISIS detector. Each spectrum was recorded at a counting time of $100 \mathrm{~s}$.

Scanning electron Microscopy (SEM) images were collected in a ZEISS Ultra-55 field-emission scanning electron microscope. All the images were acquired at an accelerated voltage of $2 \mathrm{kV}$ using an InLens detector.

Powder X-ray diffraction (XRD) patterns were recorded in a Panalytical X'pert PRO diffractometer ( $\mathrm{X}^{\prime}$ Celerator detector in a Bragg-Brentano geometry). Diffractograms were collected using $\mathrm{K}_{a 1}$ radiation of $\mathrm{Cu}$.

FTIR spectra were collected in the $4000-400 \mathrm{~cm}^{-1}$ spectral region, in a Nicolet 205xB spectrophotometer. Spectra were measured at a resolution of $1 \mathrm{~cm}^{-1}$ and 
128 accumulations per scan. Samples were diluted in $\mathrm{KBr}$ and pressed into pellets prior to measurements.

Temperature programmed oxidation experiments were carried out in a TPD/2900 instrument (Micromeritics). $0.150 \mathrm{~g}$ of as-synthesized materials were introduced in a quartz reactor and heat-treated at a heating-rate of $10{ }^{\circ} \mathrm{C} \mathrm{min}-1$ in air flow. Released species were analysed by a mass spectrometer connected at the output of the system.

X-ray photoelectron spectroscopy (XPS) analyses were carried out in a SPECS spectrometer equipped with a Phoibos 150 MCD-9 detector. Spectra were recorded at ultra-high vacuum $\left(10^{-9} \mathrm{mbar}\right)$ using a non-monochromatic AlKa (1486.6 eV) X-ray source and an analyser pass energy of $50 \mathrm{eV}$ (X-ray power of 100 W). Data treatment was performed with CasaXPS software after Shirley-type background subtraction. All the signals were referenced to C1s signal at 284.5 $\mathrm{eV}$.

CO-adsorption FTIR spectroscopy was performed at $77 \mathrm{~K}$ in a Perkin-Elmer PE 100 spectrometer, equipped with an MCT detector. Spectra were collected in transmission mode, at a resolution of $0.5 \mathrm{~cm}^{-1}$ (256 accumulations per scan). W$\mathrm{Nb}-\mathrm{O}$ oxides (heat-treated at $550{ }^{\circ} \mathrm{C}$ in $\mathrm{N}_{2}$ ) were pressed into self-supported wafers of ca. $20 \mathrm{~g} \mathrm{~cm}^{-2}$, and introduced inside the IR cell connected to a vacuum system. Prior to $\mathrm{CO}$ adsorption, the samples were activated in $\mathrm{O}_{2}$ atmosphere (200 mbar) at $300^{\circ} \mathrm{C}$ for $2 \mathrm{~h}$, and subsequently cooled down to room temperature. Then the cell was evacuated $\left(P=5.10^{-6}\right.$ mbar $)$ and temperature was further decreased down to $77 \mathrm{~K}$ (2 mbar of He were admitted to promote heat-transfer during cooling). Once a temperature of $77 \mathrm{~K}$ is reached, a spectrum of the activated sample prior to $\mathrm{CO}$ adsorption is collected. Afterwards increasing 
amounts of $\mathrm{CO}$ are admitted into the cell, and spectra at each equilibrium pressure $\left(P_{e q}=0.001-6.4\right.$ mbar $)$ are measured. Finally, the cell is evacuated and the process is monitored by recording spectra at decreasing equilibrium pressures $\left(P_{\text {eq }}=0.1-10^{-6} \mathrm{mbar}\right)$. In some cases, the results are presented as background-subtracted spectra, considering the spectrum of the activated samples recorded at $77 \mathrm{~K}$ as the background.

\section{Catalytic tests}

Catalytic tests in the gas-phase dehydration of glycerol were conducted in a fixedbed reactor at $320^{\circ} \mathrm{C}$, atmospheric pressure, and a contact time, W/F, of $81 \mathrm{~g}_{\text {cat }}$ h (molglycerol $)^{-1}$, with an Glycerol/ $\mathrm{O}_{2} / \mathrm{H}_{2} \mathrm{O} / \mathrm{He}$ molar ratio of $2 / 4 / 40 / 54$. The output stream was then bubbled in a condensation system which was maintain at a temperature of $0-3^{\circ} \mathrm{C}$. Analysis of reactants and products have been carried out by gas chromatography. ${ }^{31}$ Condensed liquid products were analysed in a Varian 3900 gas chromatograph equipped with a $100 \%$ dimethylpolysiloxane capillary column $(100 \mathrm{~m} \times 0.25 \mathrm{~mm} \times 0.5 \mu \mathrm{m})$, while the remaining gaseous stream was analysed in an on-line HP 6980 gas chromatograph equipped with two columns: i) molecular sieve (5 $\AA$, 3.0 m length) and; ii) Porapak Q (3 m length). 


\section{Results and discussion}

\section{Effects of thermal treatments on W-Nb-O oxides}

To deal with structural and chemical consequences of heat-treatments, asprepared and heat-treated $\mathrm{W}-\mathrm{Nb}-\mathrm{O}$ oxides were analysed by several physicochemical techniques.

Figures 1A displays XRD patterns of heat-treated $\mathrm{W}-\mathrm{Nb}-\mathrm{O}$ oxides. For comparison, XRD patterns of the corresponding as-prepared samples are included in Figure S1-A (Supporting Information). As indicated previously, ${ }^{22}$ the incorporation of $\mathrm{Nb}^{5+}$ within the hexagonal tungsten bronze, $h-\mathrm{WO}_{3}$, framework (showing three and six-membered channels along [001] direction) promotes: i) the stabilisation of the hexagonal tungsten bronze structure (at low Nb contents) and; ii) the loss of long-range order in the $a b$ plane of the structure at increasing $\mathrm{Nb}$ concentrations in the materials. This loss of periodicity, which is observed in both heat-treated (Fig. 1A, patterns $d$ to $h$ ) and as-prepared samples (Fig. S1A), gives rise to the so-called pseudocrystalline $\mathrm{W}-\mathrm{Nb}-\mathrm{O}$ oxides, ordered just along $c$ direction.

Figure $1 \mathrm{~B}$ shows $\mathrm{XRD}$ patterns in the $2 \theta$ range $3-17^{\circ}$ for heat-treated materials, whereas the corresponding XRD patterns of as-prepared samples are presented in Figure S1-B. Despite the loss of long-range order observed, as-prepared pseudocrystalline materials present two broad features in this region (Fig. S1-B, patterns $\mathrm{c}$ to $\mathrm{f}$ marked with an asterisk). Interestingly, these two broad lines at low angles could indicate some long-range order, which could be related with the presence of nascent $\mathrm{Cs}_{0.5}\left[\mathrm{~W}_{2.5} \mathrm{Nb}_{2.5} \mathrm{O}_{14}\right]$-type phase (ICDD: 01-076-5882). This polymorph presents some differences with respect to the hexagonal tungsten 
bronze structure: ${ }^{36,37}$ i) it shows five-, six- and seven-membered channels; and ii) $\mathrm{Nb}^{5+}$ is incorporated within the pentagonal channel, in the form of $\mathrm{NbO}_{7}$ bipyramids (Figure 1B).

Fig. 1. A) $X R D$ patterns in the $2 \theta$ region $5-65^{\circ}$ of $\mathrm{W}-\mathrm{Nb}-\mathrm{O}$ oxides heat-treated at $550^{\circ} \mathrm{C}$, except sample WOx, which was heat-treated at $450^{\circ} \mathrm{C}$. Samples: a) WOx; b) WNb29; c) WNb62; d) WNb80; e) WNb95; f) Nb100. B) XRD patterns of W$\mathrm{Nb}-\mathrm{O}$ oxides in the $3-17^{\circ} 2 \theta$ region. For comparison, the pattern of an orthorhombic Cs0.5[W2.5 $\left.\mathrm{Nb}_{2.5} \mathrm{O}_{14}\right]$-type phase ${ }^{36,37}$ is also included (g).

These channels (either the heptagonal and/or hexagonal) are usually occupied by electropositive metals (like alkaline metal cations, ${ }^{38,39}$ for instance, $\mathrm{Cs}^{+}$in $\left.\mathrm{Cs}_{0.5}\left[\mathrm{~W}_{2.5} \mathrm{Nb}_{2.5} \mathrm{O}_{14}\right]\right)$, although other types of species, like rare earth cations, ${ }^{18}$ or even ammonium ions, ${ }^{40}$ can be incorporated. In our case, since ammonium cations are present in the reaction media, they could be easily accommodated within the hexagonal and/or heptagonal rings of these bronze-like frameworks, and subsequently eliminated after heat treatments.

Interestingly, heat-treated samples present some differences in the low-angle diffraction region (Fig. 1B), with respect to as-prepared oxides (Figure 1S-B). Particularly, it can be noted that heat-treated pseudocrystalline samples (i.e. those presenting high $\mathrm{Nb}$ at. \%, > $62 \%$ ) loss the above-mentioned broad diffraction lines (Fig. 1B, patterns $\mathrm{d}$ to f). On the other hand, WNb62, with $\mathrm{Nb}$ at. $\%$ of ca. $50 \%$, retains these low-angle signals (Fig. 1B, patterns c), which is related to an emerging long-range order in the materials. In fact, in a previous 
work we already observed the formation of nanoparticles $(5-10 \mathrm{~nm})$ displaying a $\mathrm{Cs}_{0.5}\left[\mathrm{~W}_{2.5} \mathrm{Nb}_{2.5} \mathrm{O}\right.$ 14]-type structure, at $\mathrm{Nb} /(\mathrm{W}+\mathrm{Nb})$ ratios close to $0.5 .{ }^{23}$

To further understand the effect of the incorporation of $\mathrm{Nb}$ in $\mathrm{W}-\mathrm{Nb}-\mathrm{O}$ system, the samples were heat-treated at higher temperatures $\left(800^{\circ} \mathrm{C}\right.$ in $\left.\mathrm{N}_{2}\right)$, and analysed by XRD (Fig. 2). It can be observed that hexagonal W-Nb-O oxides, with low $\mathrm{Nb}$ contents (i.e. WOx and WNb29 samples), undergo a phase transition to a $\mathrm{ReO}_{3}$ type structures (JCPDS: 00-020-1324) (Fig. 2, patterns a and b). On the other hand, at both intermediate or high $\mathrm{Nb}$ contents, the pseudocrystalline oxides $\mathrm{W}$ $\mathrm{Nb}-\mathrm{O}$ evolve to tetragonal tungsten bronze-type (TTB) structures (JCPDS: 01075-0560) (samples WNb62 and WNb80; Fig. 2, patterns $\mathrm{c}$ and d) or $\mathrm{T}^{-\mathrm{Nb}_{2} \mathrm{O}_{5}-}$ type (JCPDS: 00-30-0873) (samples WNb95 and Nb100; Fig. 2, patterns e and f). Interestingly, these latter phases show the presence of $\mathrm{NbO}_{7}$ pentagonal bipyramids as a common structural motif. Therefore, according to the structural evolution of $\mathrm{W}-\mathrm{Nb}-\mathrm{O}$ oxides at medium-high $\mathrm{Nb}$ contents, pseudocrystalline materials seem to show more similarities to those $\mathrm{NbO}_{7}$ containing bronze-like structures, rather than the hexagonal tungsten bronze.

Fig. 2. $X R D$ patterns of selected $\mathrm{W}-\mathrm{Nb}-\mathrm{O}$ oxides heat-treated at $800^{\circ} \mathrm{C}$ in $\mathrm{N}_{2}$. a) WOx; b) WNb29; c) WNb62; d) WNb80; WNb95; f) Nb100.

This fact should have consequences in the chemical nature of the constituent elements (i.e. $\mathrm{W}$ and $\mathrm{Nb}$ ), according to the different environment of $\mathrm{MO}_{6}$ octahedra in these $\mathrm{NbO}_{7}$ containing crystal structures. In this sense, hexagonal tungsten bronze structure shows only vertex-sharing octahedra, meanwhile pentagonal bipyramid-containing structures display a higher concentration of 
edge-sharing motifs (i.e. those octahedra located at the equatorial edges of the bipyramids; see insets in Figure 2).

Figure 3 displays FTIR spectra $\left(1500-400 \mathrm{~cm}^{-1}\right)$ of as-prepared and heat-treated W-Nb-O oxides (Figs. 3A and 3B, respectively). All materials present high intensity bands in the $1000-400 \mathrm{~cm}^{-1}$ region, which can be assigned to $M=0$ and M-O-M stretching modes of bronze-like metal oxides. ${ }^{12,13}$ In addition, as-prepared materials display a narrow band at ca. $1402 \mathrm{~cm}^{-1}$, which can be assigned to deformation $\delta_{(\mathrm{NH})}$ modes of incorporated ammonium cations (Fig. 3A).

Fig. 3. FTIR spectra of as-prepared (A) and heat-treated (B) W-Nb-O oxides; and temperature-programmed oxidation (TPO) profiles of selected as-prepared W$\mathrm{Nb}-\mathrm{O}$ samples $(\mathrm{C})$, following the characteristic mass of ammonia $(\mathrm{m} / \mathrm{z}=15)$. Samples: WOx (a); WNb29 (b); WNb62 (c); Nb100 (d). As indicated in text, sample WOx was heated-treated at $450^{\circ} \mathrm{C}$ whereas the rest of samples were heat-treated at $550^{\circ} \mathrm{C}$.

After activation at $550^{\circ} \mathrm{C}$ in $\mathrm{N}_{2}$, this signal disappears for all $\mathrm{Nb}$-containing samples (Fig. 3B, spectra b to d). Nevertheless, WOx sample (heat-treated at $450^{\circ} \mathrm{C}$ in $\mathrm{N}_{2}$ ) still displays some remaining $\mathrm{NH}_{4}{ }^{+}$species (see Fig. 3B, spectrum a). These ammonium species are reported to be necessary to keep $h$-WO 3 structure stable. ${ }^{40}$

The activation process (i.e. ammonium release during thermal treatments) has been studied by temperature-programmed oxidation (TPO). The corresponding profiles for some selected materials were recorded by following the characteristic 
mass of ammonia ( $\mathrm{m} / \mathrm{z}=15)$ by mass spectrometry (Fig. $3 \mathbf{C})$. Interestingly, a shift of the maximum in $\mathrm{m} / \mathrm{z}=15$ TPO profiles to lower temperatures is observed when the $\mathrm{Nb}$-content in the materials increases (Fig. 3C). This means that, as we incorporate $\mathrm{Nb}^{5+}$ in $\mathrm{W}-\mathrm{Nb}-\mathrm{O}$ oxides, ammonium species are more easily eliminated by thermal treatments. This observation could be a consequence of a decreasing particle size in Nb-containing samples, as deduced from Scanning Electron Microscopy images of W-Nb-O series (Fig. S2, Supporting Information). In this context, a smaller particle size will decrease diffusion paths of ammonium within the structural channels of $\mathrm{W}-\mathrm{Nb}-\mathrm{O}$ oxides, facilitating their elimination by thermal treatments. However, and as will be discussed later, it cannot be ruled out that the elimination of ammonium ions at higher temperatures for tungstenrich samples could also be a consequence of greater interaction with the solid (presence of Brönsted centres, as observed in zeolitic materials). ${ }^{41}$ In addition to ammonia, some water was also detected by mass spectrometry during these experiments (Fig. S3). Signals at low (100-200 $\left.{ }^{\circ} \mathrm{C}\right)$ and medium-high $(250-400$ $\left.{ }^{\circ} \mathrm{C}\right)$ temperatures can be ascribed to physisorbed water, and water released from the structural channels, respectively (Fig. S3).

\section{Surface analysis of $\mathrm{W}-\mathrm{Nb}-\mathrm{O}$ oxides}

Surface composition and chemical nature of $\mathrm{W}-\mathrm{Nb}-\mathrm{O}$ oxides were studied by $\mathrm{X}$ Ray Photoelectron Spectroscopy (XPS). For comparison, Nb-free sample, WOx, heat-treated at $450^{\circ} \mathrm{C}$, has also been included. The whole series displays a throughout slightly reduced surface $\mathrm{Nb}$ content (determined by XPS) compared to that measured by XEDS (Table 1). This indicates a depletion of Nb-content on the catalyst surface. 
Figure 4 displays $\mathrm{W} 4 f$ core-level spectra of $\mathrm{W}-\mathrm{Nb}-\mathrm{O}$ oxides. Considering tungsten species, all the samples show a major $W 4 f_{7 / 2}$ peak at binding energies in the range 35.2-35.8 eV, which can be assigned to the presence of $\mathrm{W}^{6+}$ species. ${ }^{40,42,43}$ An additional $W 4 f_{7 / 2}$ peak, located at binding energies of ca. 34.2$34.7 \mathrm{eV}$ is also observed, which can be ascribed to the presence of $\mathrm{W}^{5+}$ species on the catalyst surface. ${ }^{40,42,43}$

On the contrary, a different trend is observed in the case of niobium surface species. We must mention that the Nb $3 d$ XPS core-level spectra of W-Nb-O oxides shows only a single $\mathrm{Nb} 3 d_{5 / 2}$ XPS peak (appearing at B.E.= 206.8-207.1 $\mathrm{eV}$ ) (Figure S4), indicating the presence of $\mathrm{Nb}^{5+}$ species. ${ }^{44}$ Although not significant differences are observed in terms of line-shape, a slight decrease in binding energy of $\mathrm{Nb} 3 \mathrm{~d}$ signal is detected when $\mathrm{Nb}$-content increases (from 207.0 to $206.8 \mathrm{eV}$ ). This finding could indicate a decrease in the mean oxidation state of niobium species, as reported previously. ${ }^{45}$

As far as tungsten bronze based materials are concerned, they can be understood as partially reduced phases, in which tungsten can be present in a wide variety of oxidation states..$^{1,2}$ In this context, undoped WOx sample shows a significant amount of $\mathrm{W}^{5+}$ on the catalyst surface (Fig. 4, spectrum a), with a $\mathrm{W}^{5+} /\left(\mathrm{W}^{6+}+\mathrm{W}^{5+}\right)$ surface atomic ratio of ca. 0.14 (Table 1$)$. In tungsten-rich samples (up to 29 at. \% of niobium), the XPS signal due to $\mathrm{W}^{5+}$ decreases (Fig. 4, spectrum b), presenting a $\mathrm{W}^{5+} /\left(\mathrm{W}^{6+}+\mathrm{W}^{5+}\right)$ surface atomic ratio of ca. 0.05 (Table 1). However, the incorporation of higher amounts of $\mathrm{Nb}^{5+}(\mathrm{Nb}$ at. \% $>30)$ leads to a progressive increase of the intensity of $\mathrm{W}^{5+}$ XPS peak (Fig. 4, spectra $c$ to e), observing $\mathrm{W}^{5+} /\left(\mathrm{W}^{6+}+\mathrm{W}^{5+}\right.$ surface atomic ratios of $0.08-0.34$ (Table 1). 
Fig. 4. $\mathrm{W} 4 \mathrm{f}$ core-level $\mathrm{XPS}$ spectra of $\mathrm{W}-\mathrm{Nb}-\mathrm{O}$ oxides heat-treated at $550^{\circ} \mathrm{C}$ in $\mathrm{N}_{2}$ : b) WNb29; c) WNb62; d) WNb80; e) WNb95. For comparison, $\mathrm{Nb}$-free samples heat-treated at $450^{\circ} \mathrm{C}$, WOx (a), is also included.

This suggests that the further incorporation of $\mathrm{Nb}^{5+}$ within the structure of the tungsten oxide bronze $\left(\mathrm{Nb}\right.$ at. \% > 30) could lead to the stabilisation of new $\mathrm{W}^{5+}$ surface species. In fact, we have to take into consideration that heat-treatments of $\mathrm{Nb}$-containing samples (activated at $550^{\circ} \mathrm{C}$ in $\mathrm{N}_{2}$ ) differ for $\mathrm{Nb}$-free tungsten oxide (WOx sample, heat-treated at $450^{\circ} \mathrm{C}$ ). This implies that, unlike in the case of $h$ - $\mathrm{WO}_{3}$ phase, $\mathrm{W}^{5+}$ species in $\mathrm{W}-\mathrm{Nb}-\mathrm{O}$ with relatively high $\mathrm{Nb}$ contents show a higher thermal stability; i.e., they remain stable after higher temperature heat treatments $\left(550^{\circ} \mathrm{C}\right)($ Fig. 4 , spectra $\mathrm{c}$ to e).

The correlation between the thermal stability of $h-\mathrm{WO}_{3}$ phase and the presence of $\mathrm{NH}_{4}{ }^{+}$within the hexagonal channels (which is also linked to the presence $\mathrm{W}^{5+}$ and other reduced species) has already been reported elsewhere. ${ }^{40}$ The elimination of $\mathrm{NH}_{4}{ }^{+}$ions from the channels due to high temperatures heat treatments $\left(>450{ }^{\circ} \mathrm{C}\right)$ and the concomitant oxidation of those $\mathrm{W}^{5+}$ species into $\mathrm{W}^{6+}$, leads to the phase transition to $m-\mathrm{WO}_{3}$, showing low surface areas and low concentration of surface acid sites. ${ }^{10,29,40}$ In this particular example, in which $\mathrm{Nb}$ is absent in the formulation, the partially reduced nature of the crystal phase is maintained by the presence of those ammonium ions in the hexagonal channels, associated to $\mathrm{W}^{5+}$ sites. Once those ammonium ions are completely eliminated (for example, by high temperature heat treatments), the hexagonal structure is no longer stable. Then, this means that bronze-type phases are thermally stable as far as they are able to retain their partially reduced nature. 
An interesting strategy to increase the thermal stability of the hexagonal phase consists in the partial substitution of tungsten species by other transition metals, especially by those elements showing a maximum oxidation state lower than $6+$ (for instance, vanadium, ${ }^{10-13,19}$ tantalum ${ }^{26}$ or titanium, ${ }^{27,28}$ which are stable up to $\left.500-600^{\circ} \mathrm{C}\right)$. This way, the incorporation of these elements will help to keep the partially reduce nature of the materials, thus increasing the thermal stability of $h$ $\mathrm{WO}_{3}$ phase. However, in the latter cases, it is not possible to incorporate high amounts of dopant within the structure. Dopant contents exceeding the maximum theoretical value for the hexagonal tungsten bronze structure $\left(h-\mathrm{W}_{1-\mathrm{x}} \mathrm{M}_{\mathrm{x}} \mathrm{O}_{3}\right.$; $\mathrm{x}=0.33$ and $\mathrm{M}=\mathrm{V}, \mathrm{Ti})$ give rise to anatase-type $\mathrm{TiO}_{2}$ nanoparticles ${ }^{28}$ or extraframework $\mathrm{VO}_{\mathrm{x}}$ species. ${ }^{10}$

The case of $\mathrm{W}-\mathrm{Nb}-\mathrm{O}$ system is completely different, since niobium is incorporated within the crystal framework throughout all the compositional range, giving rise to a loss of long-range order in the $a b$ plane of the structure. ${ }^{23}$ In fact, those pseudocrystalline oxides obtained at high niobium contents ( $\mathrm{Nb}$ content $>50$ at. \%) can no longer be considered as a "hexagonal tungsten bronze" due to the loss of periodicity in the $a b$ plane. The way the system has to keep its reduced state is, in this case, to favour the phase transition to the pseudocrystalline-like structures.

In summary, the incorporation of relatively low amounts of niobium atoms stabilizes the hexagonal tungsten bronze, through the isomorphic substitution of $\mathrm{W}^{5+}$ by $\mathrm{Nb}^{5+}$. On the other hand, the further incorporation of $\mathrm{Nb}^{5+}$ leads to the stabilisation of $\mathrm{W}^{5+}$ species at higher heat-treatment temperatures $\left(550{ }^{\circ} \mathrm{C}\right)$, but at the expense of losing periodicity along the $a b$ plane of the structure. In addition, this stabilisation of $\mathrm{W}^{5+}$ species at higher temperatures can be the consequence 
of the presence of pentagonal bipyramids $\mathrm{NbO}_{7}$ in the structure, which can share its five equatorial edges with five octahedra, leading to $\mathrm{M}_{x} \mathrm{NbO}_{7+4 \times}$ motifs $(\mathrm{M}: \mathrm{Nb}$ or $\mathrm{W}, \mathrm{x} \leq 5$ ) (see Fig. 2). These edge-sharing $\mathrm{MO}_{6}$ octahedra in the bipyramid show a very different environment comparing with those in $h-\mathrm{WO}_{3}$ or $m-\mathrm{WO}_{3}$ crystal structures. The partial occupation of these octahedral sites by tungsten could be the cause of the relatively high concentration of surface $\mathrm{W}^{5+}$ species found in pseudocrystalline materials. Paradigmatic examples of the linkage between cation coordination and oxidation states are the formation of the socalled Magneli phases or the tetragonal tungsten bronze (TTB) structure from $\mathrm{ReO}_{3}$-type polymorphs. ${ }^{46-48}$ The formation of both types of polymorphs can be understood as two interrelated processes: i) loss of oxygen (i.e. reduction) and; ii) structural modifications (i.e. rotation in the case of TTB formation, or condensation, in the case of the formation of Magneli phases) (Fig. S5). In this context, both the presence of defects (like O-deficient sites) and the specific structural motifs (like the pentagonal bipyramid) are connected with the incorporation of reduced metal species within the crystal framework (for instance, $\left.\mathrm{W}^{5+}\right)$.

According to this, the nature of surface oxygen species in $\mathrm{W}-\mathrm{Nb}-\mathrm{O}$ oxides were also studied by means of XPS (Fig. 5). O 1s core level spectra display three different signals, which are usually interpreted in terms of the nature of surface oxygen. ${ }^{49}$ High intensity O1s XPS peak appearing at low binding energy (BE= 529.8-530.2 eV) is generally assigned to lattice oxygen. ${ }^{49-51}$ On the other hand, signals appearing at B.E. of ca. 531.6-531.9 and 532.8-533.0 eV. They are usually ascribed to defects, such as oxygen species near $\mathrm{O}^{2-}$ vacancies or surface $-\mathrm{OH}$ groups, respectively. ${ }^{49}$ In addition, an increase in the relative 
intensity of these signals is observed in Nb-containing materials, suggesting that the incorporation of niobium favours the formation of defect sites.

Since the presence of surface $\mathrm{W}^{5+}$ or $\mathrm{Nb}^{5+}$ can have a great influence on the nature of surface acid sites, selected samples were analysed by means of lowtemperature (77 K) FTIR spectroscopy of adsorbed CO.

Fig. 5. $\mathrm{O} 1 \mathrm{~s}$ core-level XPS spectra of $\mathrm{W}-\mathrm{Nb}-\mathrm{O}$ oxides heat-treated at $550^{\circ} \mathrm{C}$ in $\mathrm{N}_{2}$ : b) WNb29; c) WN62; d) WNb80; e) WNb95; f) Nb100. For comparison, Nbfree sample (a), i.e. WOx heat-treated at $450^{\circ} \mathrm{C}$, is also included.

At low temperatures carbon monoxide (CO) can act as a basic probe molecule, by interacting with both surface Brönsted (via H-bond) and Lewis (i.e. coordinatively unsaturated sites; CUS) acid sites. These interactions lead to frequency shifts of the gas-phase $\mathrm{v}(\mathrm{CO})$ stretching mode $\left(\mathrm{ca} .2143 \mathrm{~cm}^{-1}\right)$. Also, due to the interaction via $\mathrm{H}$-bond with $\mathrm{O}-\mathrm{H}$ and/or $\mathrm{N}-\mathrm{H}$ groups, $\mathrm{v}(\mathrm{O}-\mathrm{H})$ and $\mathrm{v}(\mathrm{N}-$ H) stretching modes $\left(3800-3200 \mathrm{~cm}^{-1}\right)$ shift to lower frequencies (due to the formation of weaker $\mathrm{O}-\mathrm{H}$ or $\mathrm{N}-\mathrm{H}$ bonds), what allows to study the nature of Brönsted acid sites. ${ }^{52,53}$

Figure 6 shows the low-temperature FTIR spectra of adsorbed CO in the C-O (Fig. 6; A to C) and O-H/N-H (Fig. 6; D to F) stretching regions, at $\mathrm{CO}$ equilibrium pressures $\left(\mathrm{P}_{\mathrm{COeq}}\right)$ in the range 0-5.5 mbar, for selected heat-treated $\mathrm{W}-\mathrm{Nb}-\mathrm{O}$ materials with different $\mathrm{Nb}$ content. Depending on $\mathrm{Nb}$-content, two main trends are observed along the series. Considering $\mathrm{C}-\mathrm{O}$ stretching region (Fig. 6; A to C), and more specifically, at low CO equilibrium pressures (ca. $P_{c 0 e q}=0.02 \mathrm{mbar}$, green lines in Fig. 6), it can be observed that the pseudocrystalline WNb62 
sample presents the highest amount of $\mathrm{CO}$ adsorbed (i.e. higher coverages) (Fig. 6, C). Focusing on $\mathrm{O}-\mathrm{H}$ stretching region (Fig. 6, D to $\mathrm{F}$ ), these materials also show different OC...H-O interaction, due to the presence of Brönsted acid sites.

We must inform that $\mathrm{Nb}$-free tungsten oxide, i.e. WOx sample, displays some extra features in this $\mathrm{O}-\mathrm{H} / \mathrm{N}-\mathrm{H}$ stretching region, at ca. $3400-3300 \mathrm{~cm}^{-1}$ (Fig. 6 , D), which can be related to the presence of ammonium cations in the channels of the hexagonal tungsten bronze. ${ }^{10}$

Fig. 6. Low temperature (77K) FTIR spectra of adsorbed $C O$ in the $C-O(A-C)$ and $\mathrm{O}-\mathrm{H}(\mathrm{D}-\mathrm{F})$ stretching regions for selected $\mathrm{W}-\mathrm{Nb}-\mathrm{O}$ oxides heat-treated at 450 (WOx) or $550^{\circ} \mathrm{C}$. Samples: WOx (A,D); WNb29 (B,E); and WNb62 (C,F).

Firstly, we have analysed $\mathrm{C}-\mathrm{O}$ stretching region of the spectra. Taking into consideration the wide variation of the physicochemical features depending on $\mathrm{Nb}$-content, i.e. particle size and crystal structure (as suggested from Fig. 1 and Fig. S2, respectively), CO adsorbed spectra for $\mathrm{W}-\mathrm{Nb}-\mathrm{O}$ materials were compared at the same CO-coverage (Figs. 7 and 8 ). In this case, CO-coverage ( $\theta$ ) can be calculated from background-subtracted spectra in the C-O stretching region. CO-coverages $(\theta)$ were estimated from integrated areas of the C-O stretching region, considering a coverage $\theta=1$ when the area of the $\mathrm{C}-\mathrm{O}$ stretching modes does not vary significantly at increasing pressures (i.e. when the rotational modes of $\mathrm{CO}$ in the gas-phase are observed in the spectra). The 
variation of CO-coverage with equilibrium pressure (adsorption isotherm) for selected samples are shown in Figure $\mathbf{S 6 .}$

Fig. 7. CO-adsorption FTIR spectra (background-subtracted) and the corresponding deconvoluted spectra recorded at low temperature $(77 \mathrm{~K})$ at a $\mathrm{CO}$ coverage of $\theta=0.25(A)$ and $\theta=0.65$ (B) for selected samples: (a) WOx; b) WNb29; c) WNb62. Fitted peaks are assigned to $\mathrm{C}-\mathrm{O}$ stretching vibrational modes of physisorbed CO (red), or CO bonded to Brönsted (blue) or Lewis (green) acid sites.

Figure 7 displays background-subtracted FTIR spectra in the C-O region at low $(\theta=0.25$, Fig. 7A) and high CO-coverage (ca. $\theta=0.65$, Fig. 7B) collected at 77 K. The materials show bands in three different frequency regimes: $2135-2145$, 2150-2170 and $2175-2200 \mathrm{~cm}^{-1}$; which are typically assigned to physisorbed CO, and $\mathrm{CO}$ interacting with Brönsted and Lewis surface acid sites, respectively. ${ }^{52}$

To deal with intensity changes in the $\mathrm{O}-\mathrm{H}$ and $\mathrm{N}-\mathrm{H}$ stretching region during $\mathrm{CO}-$ adsorption, background-subtracted spectra have been used, especially to analyse $\mathrm{CO} \ldots \mathrm{NH}$ interactions. Figure 8 displays background-subtracted FTIR spectra of adsorbed $\mathrm{CO}$ in the $\mathrm{O}-\mathrm{H}$ and $\mathrm{N}-\mathrm{H}$ stretching region for WOx (heattreated at $450^{\circ} \mathrm{C}$ ), and for $\mathrm{WNb} 29$ and WNb62 samples heat-treated at $550^{\circ} \mathrm{C}$.

Fig. 8. Background-subtracted FTIR spectra of adsorbed $\mathrm{CO}$ in the $\mathrm{OH} / \mathrm{NH}$ stretching region for selected W-Nb-O oxides: A) WOx; B) WNb29; C) WNb62. 
All the materials show $\mathrm{CO}$... HO interactions, leading to a shift in $\mathrm{O}-\mathrm{H}$ stretching modes to higher frequencies (see negative and positive FTIR bands at 3592$3674 \mathrm{~cm}^{-1}$ and 3465-3492 $\mathrm{cm}^{-1}$, respectively, in Fig. 8). In addition, Nb-free WOx oxide (with an $h-\mathrm{WO}_{3}$ structure) presents an extra feature in the spectra during CO-adsorption (Fig. 8A).

Specifically, a negative band appears at $3375 \mathrm{~cm}^{-1}$, which is shifted to higher frequencies at increasing CO pressures, up to 3340 and $3307 \mathrm{~cm}^{-1}$. We can assign this extra feature to $\mathrm{CO}$...HN interactions, which provoke a weakening of $\mathrm{N}-\mathrm{H}$ bonds of ammonium cations in this material. This fact indicates a considerable Brönsted acidity of ammonium species in the $\mathrm{Nb}$-free hexagonal tungsten bronze, which are present due to the lower heat-treatment temperature applied $\left(450^{\circ} \mathrm{C}\right)$. A similar effect has been reported for an ammonium exchanged ferrierite zeolite. ${ }^{54}$

After CO-adsorption, samples were outgassed at low temperature $(77 \mathrm{~K})$ and FTIR spectra were collected during the process (Fig. 9). Figure 9A displays background-subtracted FTIR spectra recorded at decreasing equilibrium pressures in the $\mathrm{C}-\mathrm{O}$ stretching region. Evacuation at low temperatures leads to a progressive decrease of $\mathrm{C}-\mathrm{O}$ stretching IR bands assigned to $\mathrm{CO}$ interacting with both Brönsted and Lewis surface acid sites, and physisorbed CO.

Interestingly, WNb29 sample, with a hexagonal tungsten bronze structure, presents no signals in the $\mathrm{C}-\mathrm{O}$ stretching region when it is treated at high vacuum (ca. $10^{-6}$ mbar) (Fig. 9A, spectra in b). On the other hand, both WOx and WNb62 samples show a remaining signal at 2195 and $2197 \mathrm{~cm}^{-1}$, respectively, at such low pressures (i.e. $10^{-6}$ mbar). This signal can be ascribed to the presence of 
strong surface Lewis acid sites, most likely associated with the presence of $\mathrm{W}^{5+}$ species according to XPS results (Fig. 4, spectra a-c).

O-H stretching region was also analysed during evacuation (Fig. 9B). Decreasing the pressure in the IR-cell leads to the recovery of the original spectra for $\mathrm{Nb}$ containing samples, as it can be deduced from the flat profile of backgroundsubtracted FTIR spectra of WNb29 and WNb62 oxides (Fig. 9B, spectra in b and in c). On the contrary, the background-subtracted spectra collected at $10^{-6} \mathrm{mbar}$ for $\mathrm{Nb}$-free sample, i.e. WOx oxide, shows a group of negative signals (Figure 9B, spectra in a).

Fig. 9. Background-subtracted FTIR spectra during $\mathrm{CO}$ evacuation at equilibrium pressures of ca. 0.05 mbar (dotted blue spectra), 10-2 mbar (green spectra) and $10^{-6}$ mbar (red spectra) recorded at $77 \mathrm{~K}$ for selected $\mathrm{W}-\mathrm{Nb}-\mathrm{O}$ oxides: A) C-O stretching region; B) O-H stretching region. Samples: a) WOx; b) WN29; c) WNb62.

This fact indicates changes in the surface nature of the hexagonal tungsten bronze during the experiment. Specifically, the sample presents a series of negative bands centred at ca. 3592, 3373, 3200, 3047 and $2812 \mathrm{~cm}^{-1}$ (Fig. 9B, spectra a). The high frequency negative signal at $3592 \mathrm{~cm}^{-1}$ can be assigned to the loss of surface $\mathrm{O}-\mathrm{H}$ groups during desorption. Interestingly, the rest of negative bands in the spectra recorded at $10^{-6} \mathrm{mbar}$ are consistent with the elimination of ammonium cations from the channels. In fact, the band at $3373 \mathrm{~cm}^{-}$ ${ }^{1}$ corresponds to the $\mathrm{N}-\mathrm{H}$ stretching vibration of $\mathrm{NH}_{4}{ }^{+}$cations, while signals at ca. 
3200,3047 and $2812 \mathrm{~cm}^{-1}$ can be assigned to $\mathrm{H}$-bonded $\mathrm{NH}$ groups of ammonium ions. ${ }^{54,55}$

To illustrate this, the catalytic performance in the gas-phase dehydration of glycerol to acrolein for some selected W-Nb-O oxides, heat-treated at $550^{\circ} \mathrm{C}$, is shown in Table 2. It is well known that the transformation of glycerol to acrolein by a dehydration mechanism takes place via a two-step process (starting with an intramolecular dehydration of the internal hydroxyl group of glycerol and, followed by tautomerisation and subsequent dehydration of the terminal hydroxyl group) $)^{56}$ by using solid acid catalysts with appropriate nature and distribution of acid sites. ${ }^{11,13,23,57,58}$ For this system, the selectivity profiles observed are highly dependent on the Brönsted/Lewis nature of the acid sites.

WNbO oxides showing a hexagonal tungsten bronze structure $\left(h-\mathrm{WO}_{3}\right)$ (i.e. WOx, WNb29, Table 2), which display a higher proportion of Brönsted acid sites, present a relatively high yield to acrolein in the gas phase aerobic dehydration of glycerol (ca. 77-78 \% yield). On the other hand, W-Nb-O materials, with a higher concentration of $\mathrm{Nb}^{5+}$ and $\mathrm{W}^{+5}$ surface species, and presenting pseudocrystalline crystal structure (i.e. materials with a higher proportion of surface Lewis acid sites), present a lower yield to acrolein (ca. 46-55 \%) (Table 2). Concomitantly, the yield to heavy compounds increases (i.e. high molecular weight compounds that are not eluted in the gas chromatograph, mainly glycerol oligomers and condensation products ${ }^{11}$ ), up to 19 and $37 \%$. In all cases, $\mathrm{CO}_{x}$ yield remains in the range $10-17 \%$, not showing a significant increase at higher concentration of $\mathrm{Nb}^{5+}$ and $\mathrm{W}^{5+}$ in the catalysts. In addition, due to the presence of molecular oxygen in the feed, minor amounts of oxygented products were detected (mainly acetaldehyde, acetic acid and acrylic acid, with a total yield of 5-8 \%). 
Table 2. Catalytic properties in the gas-phase transformation of glycerol of selected W-Nb-O oxides heat-treated at $550{ }^{\circ} \mathrm{C}$ in $\mathrm{N}_{2}$.

\begin{tabular}{|c|c|c|c|c|}
\hline \multirow[t]{2}{*}{ Sample } & \multirow[t]{2}{*}{ Crystal structure ${ }^{a}$} & \multicolumn{3}{|c|}{ Yield to products $(\%) b, c$} \\
\hline & & Acrolein & Heavy-compounds ${ }^{d}$ & $\mathrm{CO}_{\mathrm{x}}$ \\
\hline WOx & $h-\mathrm{WO}_{3}$ & 77.8 & 6.0 & 10.9 \\
\hline WNb29 & $h-\mathrm{WO}_{3}$ & 78.3 & 6.3 & 11.8 \\
\hline WNb62 & Pseudocrystalline & 66.5 & 8.7 & 16.8 \\
\hline WNb80 & Pseudocrystalline & 55.4 & 19.0 & 17.5 \\
\hline Nb100 & Pseudocrystalline & 46.8 & 37.9 & 11.9 \\
\hline
\end{tabular}

a) Crystal structure, determined by powder X-ray diffraction: hexagonal tungsten bronze $\left(h-\mathrm{WO}_{3}\right)$; and pseudocrystalline phase.

b) Reaction conditions: $\mathrm{T}=313^{\circ} \mathrm{C}$; Glycerol $/ \mathrm{O}_{2} / \mathrm{H}_{2} \mathrm{O} / \mathrm{He}$ molar ratio of 2/4/40/54; Contact time, W/F, of $81 \mathrm{~g}_{\text {cat }} \mathrm{h}$ (molglycerol $)^{-1} ;$ Time $=5 \mathrm{~h}$.

c) Yield to the main reaction products; $\mathrm{COx}=$ Carbon oxides $\left(\mathrm{CO}+\mathrm{CO}_{2}\right)$. In addition to these, acetaldehyde, acetic acid and acrylic acid were also observed, with a total selectivity of $5-8 \%$.

d) High molecular weight species that are not eluted in the gas chromatograph.

All the above-mentioned findings go in line with previous catalytic results, by which W-rich W-Nb-O oxides direct the acid-catalysed reactions towards Brönsted-catalysed pathways; meanwhile, Nb-rich materials favour Lewiscatalysed reactions. ${ }^{23}$

\section{Conclusions}

In this study, a series of $\mathrm{W}-\mathrm{Nb}-\mathrm{O}$ oxides $(\mathrm{Nb}$ at. $\%=0-100)$, with bronze-type crystal structures have been prepared by hydrothermal synthesis. Their bulk and surface physicochemical properties have been elucidated. 
The incorporation of $\mathrm{Nb}^{5+}$ has an important influence in the structural features of both as-prepared and heat-treated materials. The addition of $\mathrm{Nb}$ at.\% up to $29 \%$ leads to the crystallisation of a hexagonal tungsten bronze structure. On the other hand, higher $\mathrm{Nb}$ contents favour the formation of the so-called pseudocrystalline phases, in which long-range order in the $a b$ plane is lost. XRD analyses of asprepared pseudocrystalline materials suggest either the crystallisation, or the formation of nascent domains with a $\mathrm{Cs}_{0.5}\left[\mathrm{~W}_{2.5} \mathrm{Nb}_{2.5} \mathrm{O}_{14}\right]-$ type structure, showing both six- and seven-membered rings.

It has been observed that as-synthesized oxide bronzes present a significant amount of $\mathrm{NH}_{4}{ }^{+}$cations in the structural channels. These $\mathrm{NH}_{4}{ }^{+}$species in $\mathrm{Nb}-$ containing materials can be completely eliminated by thermal treatments $\left(550^{\circ} \mathrm{C}\right.$ under $\mathrm{N}_{2}$ flow), retaining the hexagonal bronze structure $\left(h-\mathrm{WO}_{3}\right)$ for $\mathrm{Nb}$ contents of up to $30 \%$. In the case of $\mathrm{Nb}$-free sample (WOx), the elimination of $\mathrm{NH}_{4}{ }^{+}$ species leads to the phase transition from the hexagonal to the monoclinic phase of tungsten trioxide $\left(h-\mathrm{WO}_{3} \rightarrow m-\mathrm{WO}_{3} ; \mathrm{T}>450^{\circ} \mathrm{C}\right)$. Accordingly, the incorporation of $\mathrm{Nb}^{5+}$ in samples with $\mathrm{Nb} /(\mathrm{W}+\mathrm{Nb})$ ratios lower than 0.33 : i) stabilizes the hexagonal tungsten bronze structure at higher heat-treatment temperatures ( $\mathrm{T}$ > $450^{\circ} \mathrm{C}$ ) and; ii) favours the elimination ammonium species at lower temperatures (as observed by TPO experiments).

On the other hand, the elimination of these ammonium cations at high temperatures (i.e. $550^{\circ} \mathrm{C}$ ) produce important structural modifications. Particularly the long-range nascent ordering in pseudocrystalline samples is only retained at $\mathrm{Nb}$ at. \% close to $50 \%$ after the heat-treatment (which are in fact those close to $\mathrm{Cs}_{0.5}\left[\mathrm{~W}_{2.5} \mathrm{Nb}_{2.5} \mathrm{O}_{14}\right]$ phase stoichiometry). Additionally, further increasing the heat treatment temperature up to $800^{\circ} \mathrm{C}$ gives rise to phase transitions towards $\mathrm{NbO}_{7}$ 
containing structural types in the case of $\mathrm{Nb}$-containing pseudocrystalline oxides. This fact suggests structural similarities between both pseudocrystalline and $\mathrm{NbO}_{7}$-containing phases.

Surface properties of $\mathrm{W}-\mathrm{Nb}-\mathrm{O}$ samples are also dependant on $\mathrm{Nb}$ concentration in the materials. The incorporation of relatively low amounts of niobium in the hexagonal tungsten bronze structure (at $\mathrm{Nb} /(\mathrm{W}+\mathrm{Nb})$ ratios up to 0.29$)$ leads to the decrease of surface $\mathrm{W}^{5+}$ species, suggesting the isomorphic substitution of such species by $\mathrm{Nb}^{5+}$. Conversely, the concentration of surface $\mathrm{W}^{5+}$ species increases when further amounts of $\mathrm{Nb}$ are incorporated $(\mathrm{Nb}$ at. $\%>29$ at.\%), concomitantly with the formation of pseudocrystalline materials. Hence, a possible consequence of the presence of $\mathrm{NbO}_{7}$ motifs in the pseudocrystalline samples would be the stabilisation of such $\mathrm{W}^{5+}$ surface sites (i.e. by the incorporation of tungsten in the edge-sharing octahedral sites typical of TTB ${ }^{45-47}$ or $\mathrm{Cs}_{0.5}\left[\mathrm{~W}_{2.5} \mathrm{Nb}_{2.5} \mathrm{O}_{14}\right]-$ like ${ }^{36,37}$ crystal phases).

The analysis of some selected samples by means of low-temperature (77 K) FTIR of adsorbed $\mathrm{CO}$ indicates the presence of both Brönsted and Lewis acid sites along all the compositional range of $\mathrm{W}-\mathrm{Nb}-\mathrm{O}$ series. Nevertheless, a remarkable increase in the Lewis/Brönsted surface acid site ratio is observed at high niobium contents. Strong Lewis acid sites are associated with $\mathrm{W}^{5+}$. There exists a good correlation between the proportion of Brönsted/Lewis acid sites in the catalysts, and the production of acrolein/heavy compounds during the gas-phase dehydration of glycerol.

\section{Conflicts of interest}


There are no conflicts to declare

\section{Acknowledgements}

Authors would like to acknowledge the Ministerio de Ciencia, Innovación y Universidades in Spain for the financial support (RTI2018-099668-B-C21 and SEV-2016-0683 projects), and Electron Microscopy Service at Universitat Politècnica de València for their facilities and technical support. D.D. also thanks Severo Ochoa Excellence Program for his fellowship (SVP-2014-068669). 


\section{Notes and references}

(1) D. J. M. Bevan and P. Hagenmuller, Non-Stoichiometric Compounds, Pergamon, 1973.

(2) a) H. Quan, Y. Gao and W. Wang, Inorg. Chem. Front., 2020, 7, 817-838; b) Ch.-M. Wu, S. Naseem, M.-H. Chou, J.-H. Wang and Y.-Q. Jian, Front. Mater., 2019, 6, 49.

(3) P. G. Dickens and M. F. Pye, in Intercalation Chemistry, ed. M. S. Whittingham, and A. J. Jacobson, Academic Press, 1982, pp. 539-561.

(4) R. J. D. Tilley, Int. J. Refract. Met. H., 1995, 13, 93-109.

(5) A. K. Cheetham and R. B. Von Dreele, Nature Phys. Sci., 1973, 244, 139-140.

(6) H. Obayashi and J. S. Anderson, J Solid State Chem., 1976, 17, 79-89.

(7) A. Magnéli, Nature, 1950, 165, 356-357.

(8) M. Greenblatt, in Physics and Chemistry of Low-Dimensional Inorganic Conductors, ed. C. Schlenker, J. Dumas, M. Greenblatt, S. van Smaalen, Springer US, Boston, MA, 1996, 2, 15-43.

(9) J. Chen, H. Wang, J. Deng, C. Xu and Y. Wang, J. Mat. Chem. A, 2018, 6, 8986-8991.

(10) E. García-González, M. D. Soriano, E. Urones-Garrote and J. M. López Nieto, Dalton Trans., 2014, 43, 14644-14652.

(11) M. D. Soriano, P. Concepción, J. M. López Nieto, F. Cavani, S. Guidetti and C. Trevisanut, Green Chem., 2011, 13, 2954-2962.

(12) a) T. Murayama, N. Kuramata, S. Takatama, K. Nakatani, S. Izumi, X. Yi and W. Ueda, Catal. Today, 2012, 185, 224- 229; b) K. Omata, S. Izumi, T. Murayama and W. Ueda, Catal. Today, 2013, 201, 7- 11.

(13) T. J. Thibodeau, A. S. Canney, W. J. DeSisto, M. C. Wheeler, F. G. Amar and B. G. Frederick, Appl. Catal. A Gen 2010, 388, 86-95.

(14) M. J. Sienko, in Nonstoichiometric Compounds, Advances in Chemistry Vol. 39, ed. R. Ward, American Chemical Society, 1963, Chp. 21, 224-236. 
(15) C. Yang, J.-F. Chen, X. Zeng, D. Cheng and D. Cao, Ind. Eng. Chem. Res., 2014, 53, 17981-17988.

(16) D. B. Migas, V. L. Shaposhnikov, V. N. Rodin and V. E. Borisenko, J. Appl. Phys., 2010, 108, 093713.

(17) W. Ostertag and C. V. Collins, Mat. Res. Bull., 1967, 2, 217-221.

(18) W. Ostertag, Inorg. Chem., 1966, 5, 758-760.

(19) F. O. von Rohr, A. Ryser, H. Ji, K. Stolze, J. Tao, J. J. Frick, G. R. Patzke and R. J. Cava, Chem. Eur. J., 2019, 25, 2082-2088.

(20) G. Cerretti, M. Schrade, X. Song, B. Balke, H. Lu, T. Weidner, I. Lieberwirth, M. Panthöfer, T. Norby and W. Tremel, J. Mat. Chem. A, 2017, 5, 9768-9774.

(21) K. J. Griffith, K. M. Wiaderek, G. Cibin, L. E. Marbella and C. P. Grey, Nature, 2018, 559, 556-563.

(22) K. Okumura, T. Tomiyama, S. Shirakawa, S. Ishida, T. Sanada, M. Arao and M. Niwa, J. Mater. Chem., 2011, 21, 229-235

(23) D. Delgado, A. Fernández-Arroyo, M. E. Domine, E. García-González and J. M. López Nieto, Catal. Sci. Technol., 2019, 9, 3126-3136.

(24) D. Saha, K.M.Ø Jensen, C. Tyrsted, E. D. Bøjesen, A. H. Mamakhel, A.-C. Dippel, M. Christensen and B. B. Iversen, Angew. Chem. Int. Edit., 2014, 53, 3667-3670.

(25) M. Juelsholt, T. L. Christiansen and K. M. Ø. Jensen, J. Phys. Chem. C, 2019, 123, 5110-5119.

(26) T. Murayama, N. Kuramata and W. Ueda, J. Catal., 2016, 339, 143-152.

(27) T. Murayama, K. Nakajima, J. Hirata, K. Omata, E. J. M. Hensen and W Ueda, Catal. Sci. Technol., 2017, 7, 243-250.

(28) D. Delgado, M. D. Soriano, B. Solsona, S. Zamora, S. Agouram, P. Concepción and J. M. López Nieto, Appl. Catal. A: Gen, 2019, 582, 117092. 
(29) D. Delgado, A. Chieregato, M. D. Soriano, E. Rodríguez-Aguado, L. RuizRodríguez, E. Rodríguez-Castellón and J. M. López Nieto, Eur. J. Inorg. Chem., 2018, 2018, 1204-1211.

(30) D. Delgado, A. Fernández-Arroyo, N. La Salvia, M. E. Domine and J. M. López Nieto, Chinese J. Catal. 2019, 40, 1778-1787.

(31) N. La Salvia, D. Delgado, L. Ruiz-Rodríguez, L. Nadji, A. Massó, J. M. López Nieto and Catal. Today, 2017, 296, 2-9.

(32) J. Choi, K. Moon, I. Kang, S. Kim, P. J. Yoo, K. W. Oh and J. Park, Chem. Eng. J., 2015, 281, 236-242.

(33) J. M. López Nieto, P. Botella, M. I. Vázquez and A. Dejoz, Chem. Commun., 2002, 1906-1907.

(34) M. Sadakane, K. Yamagata, K. Kodato, K. Endo, K. Toriumi, Y. Ozawa, T. Ozeki, T. Nagai, Y. Matsui, N. Sakaguchi, W. D. Pyrz, D. J. Buttrey, D. A. Blom, T. Vogt and W. Ueda, Angew. Chem. Int. Edit., 2009, 48, 3782-3786.

(35) J.B. Wagner, O. Timpe, F. A. Hamid, A. Trunschke, U. Wild, D. S. Su, R. K. Widi, S. B. A. Hamid and R. Schlögl, Top. Catal., 2006, 38, 51-58.

(36) J. Barthel, T. E. Weirich, G. Cox, H. Hibst and A. Thust, Acta Mater., 2010, 58, 3764-3772.

(37) M. D. Soriano, E. García-González, P. Concepción, C. B. Rodella and J. M. López Nieto, Cryst. Growth Des., 2017, 17, 6320-6331.

(38) P. G. Dickens and M. S. Whittingham, Q. Rev. Chem. Soc., 1968, 22, 30-44.

(39) A. Magnéli, Nature, 1952, 169, 791-792.

(40) I. M. Szilágyi, J. Madarász, G. Pokol, P. Király, G. Tárkányi, S. Saukko, J. Mizsei, A. L. Tóth, A. Szabó and K. Varga-Josepovits, Chem. Mat., 2008, 20, 4116-4125.

(41) A. B. Pinar, C. Marquez-Alvarez, M. Grande-Casas and J. Perez-Pariente, J. Catal. 2009, 263, 258-265

(42) Z. Gu, Y. Ma, T. Zhai, B. Gao, W. Yang and J. Yao, Chem.- Eur. J., 2006, 12, 7717-7723. 
(43) F. Y. Xie, L. Gong, X. Liu, Y. T. Tao, W. H. Zhang, S. H. Chen and H. Meng, J. Chen, J. Electron. Spectrosc., 2012, 185, 112-118.

(44) M. Grundner and J. Halbritter, J. Appl. Phys., 1980, 51, 397-405.

(45) H. T. Kreissl, M. M. J. Li, Y.-K. Peng, K. Nakagawa, T. J. N. Hooper, J. V. Hanna, A. Shepherd, T.-S. Wu, Y.-L. Soo and S. C. E. Tsang, J. Am. Chem. Soc., 2017, 139, 12670-12680.

(46) L. A. Bursill and B. G. Hyde, Nature Phys. Sci., 1972, 240, 122-124.

(47) L. A. Bursill and, D. J. Smith, Nature, 1984, 309, 319-321.

(48) D. B. Migas, V. L. Shaposhnikov and V. E. Borisenko, J. Appl. Phys., 2010, 108, 093714.

(49) J.-C. Dupin, D. Gonbeau, P. Vinatier and A. Levasseur, Phys. Chem. Chem. Phys. 2000, 2, 1319-1324.

(50) E. Ciftyürek, B. Smíd, Z. Li, V. Matolín and K. Schierbaum, Sensors, 2019, 19, 4737.

(51) D. A. Pawlak, M. Ito, M. Oku, K. Shimamura and T. Fukuda, J. Phys. Chem. B, 2002, 106, 504-507.

(52) K. I. Hadjiivanov and G. N. Vayssilov, Adv. Catal., 2002, 47, 307-511.

(53) A. Davydov, In Molecular Spectroscopy of Oxide Catalyst Surfaces, John Wiley \& Sons; Hoboken, 2003, 27-179.

(54) D. Perra, N. Drenchev, K. Chakarova, M. Cutrufello and K. Hadjiivanov, RSC Advances, 2014, 4, 56183-56187.

(55) A. Zecchina, L. Marchese, S. Bordiga, C. Pazè, and E. Gianotti, J. Phys. Chem. B, 1997, 101, 10128-10135.

56) B. Katryniok, S.Paul, V. Bellière-Baca, P. Rey and F. Dumeignil, Green Chem., 2010, 12, 2079-2098.

(57) G. S. Foo, D. Wei, D. S. Sholl and C. Sievers, ACS Catal., 2014, 4, 31803192.

(58) K.-H. Sung and S. Cheng, RSC Adv., 2017, 7, 41880-41888. 


\section{Caption to figures}

Figure 1. A) XRD patterns in the $2 \theta$ region $5-65^{\circ}$ of $\mathrm{W}-\mathrm{Nb}-\mathrm{O}$ oxides heat-treated at $550^{\circ} \mathrm{C}$, except sample WOx, which was heat-treated at $450{ }^{\circ} \mathrm{C}$. Samples: a) WOx; b) WNb29; c) WNb62; d) WNb80; e) WNb95; f) Nb100. B) XRD patterns of $\mathrm{W}-\mathrm{Nb}-\mathrm{O}$ oxides in the $3-17^{\circ} 2 \theta$ region. For comparison, the pattern of an orthorhombic $\mathrm{Cs}_{0.5}\left[\mathrm{~W}_{2.5} \mathrm{Nb}_{2.5} \mathrm{O}_{14}\right]$-type phase $^{37}$ is also included (g).

Figure 2. XRD patterns of selected $\mathrm{W}-\mathrm{Nb}-\mathrm{O}$ oxides heat-treated at $800^{\circ} \mathrm{C}$ in $\mathrm{N}_{2}$. a) WOx; b) WNb29; c) WNb62; d) WNb80; WNb95; f) Nb100.

Figure 3. FTIR spectra of as-prepared (A) and heat-treated (B) W-Nb-O oxides; and temperature-programmed oxidation (TPO) profiles of selected as-prepared $\mathrm{W}-\mathrm{Nb}-\mathrm{O}$ samples $(\mathrm{C})$, following the characteristic mass of ammonia $(\mathrm{m} / \mathrm{z}=15)$. Samples: WOx (a); WNb29 (b); WNb62 (c); Nb100 (d). As indicated in text, sample WOx was heated-treated at $450^{\circ} \mathrm{C}$ whereas the rest of samples were heat-treated at $550^{\circ} \mathrm{C}$.

Figure 4. W $4 f$ core-level XPS spectra of $\mathrm{W}-\mathrm{Nb}-\mathrm{O}$ oxides heat-treated at $550{ }^{\circ} \mathrm{C}$ in $\mathrm{N}_{2}$ : b) WNb29; c) WNb62; d) WNb80; e) WNb95. For comparison, $\mathrm{Nb}$-free samples heat-treated at $450^{\circ} \mathrm{C}$, WOx (a), is also included.

Figure 5. O 1s core-level XPS spectra of W-Nb-O oxides heat-treated at $550{ }^{\circ} \mathrm{C}$ in $\mathrm{N}_{2}$ : b) WNb29; c) WN62; d) WNb80; e) WNb95; f) Nb100. For comparison, Nbfree samples (a), WOx, heat-treated at $450^{\circ} \mathrm{C}$ is also included.

Figure 6. Low temperature (77K) FTIR spectra of adsorbed CO in the C-O (AC) and $\mathrm{O}-\mathrm{H}(\mathrm{D}-\mathrm{F})$ stretching regions for selected $\mathrm{W}-\mathrm{Nb}-\mathrm{O}$ oxides heat-treated at 450 (WOx) or $550^{\circ} \mathrm{C}$. Samples: WOx (A,D); WNb29 (B,E); and WNb62 (C,F).

Figure 7. CO-adsorption FTIR spectra (background-subtracted) and the corresponding deconvoluted spectra recorded at low temperature $(77 \mathrm{~K})$ at a COcoverage of $\theta=0.25(A)$ and $\theta=0.65(B)$ for selected samples: (a) WOx; b) WNb29; c) WNb62. Fitted peaks are assigned to C-O stretching vibrational modes of physisorbed CO (red), or CO bonded to Brönsted (blue) or Lewis (green) acid sites. 
Figure 8. Background-subtracted FTIR spectra of adsorbed $\mathrm{CO}$ in the $\mathrm{OH} / \mathrm{NH}$ stretching region for selected W-Nb-O oxides: A) WOx; B) WNb29; C) WNb62.

Figure 9. Background-subtracted FTIR spectra during $\mathrm{CO}$ evacuation at equilibrium pressures of ca. $0.05 \mathrm{mbar}$ (dotted blue spectra), $10^{-2} \mathrm{mbar}$ (green spectra) and $10^{-6}$ mbar (red spectra) recorded at $77 \mathrm{~K}$ for selected $\mathrm{W}-\mathrm{Nb}-\mathrm{O}$ oxides: A) C-O stretching region; B) O-H stretching region. Samples: a) WOx; b) WN29; c) WNb62. 


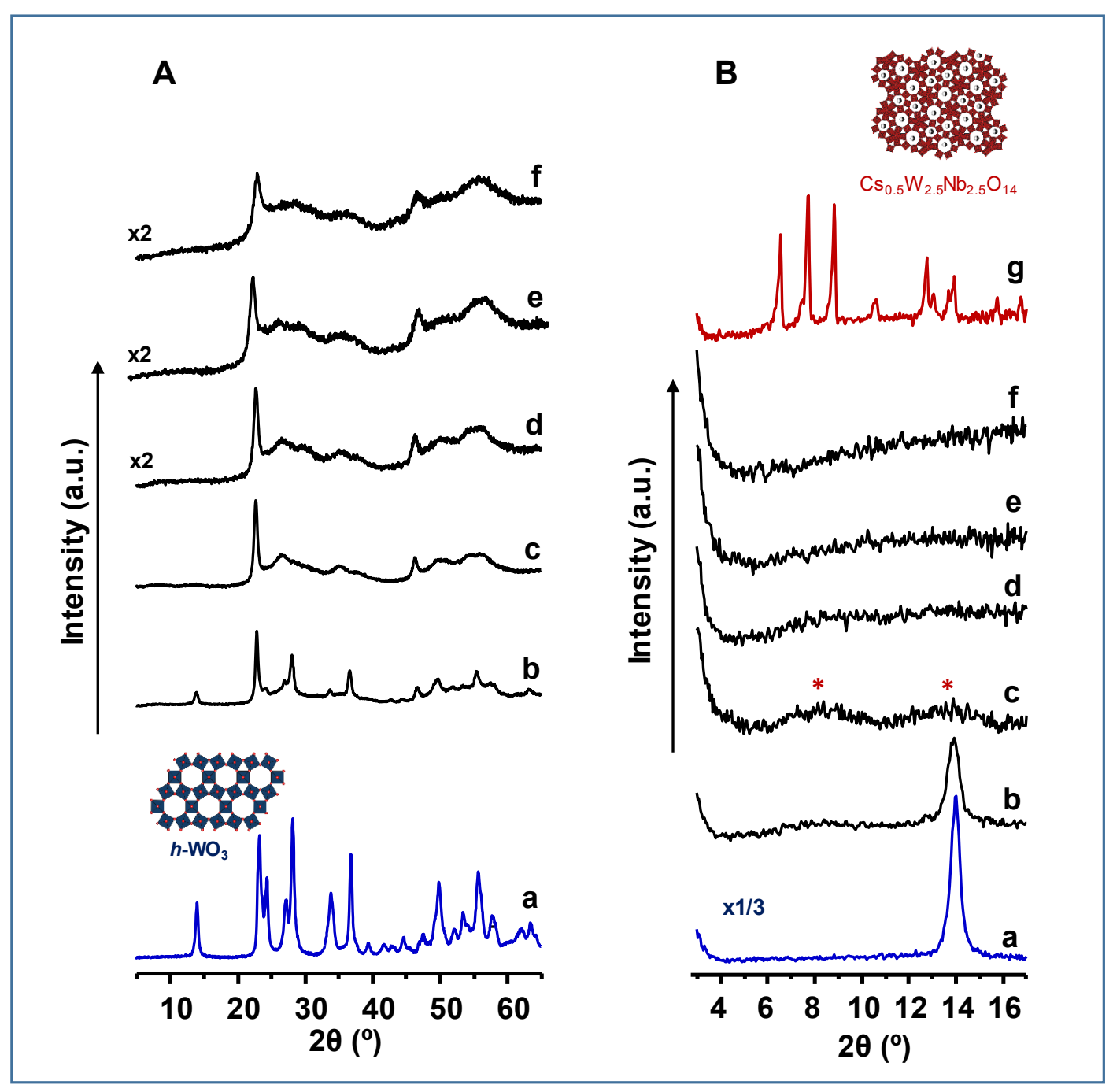

Fig. 1

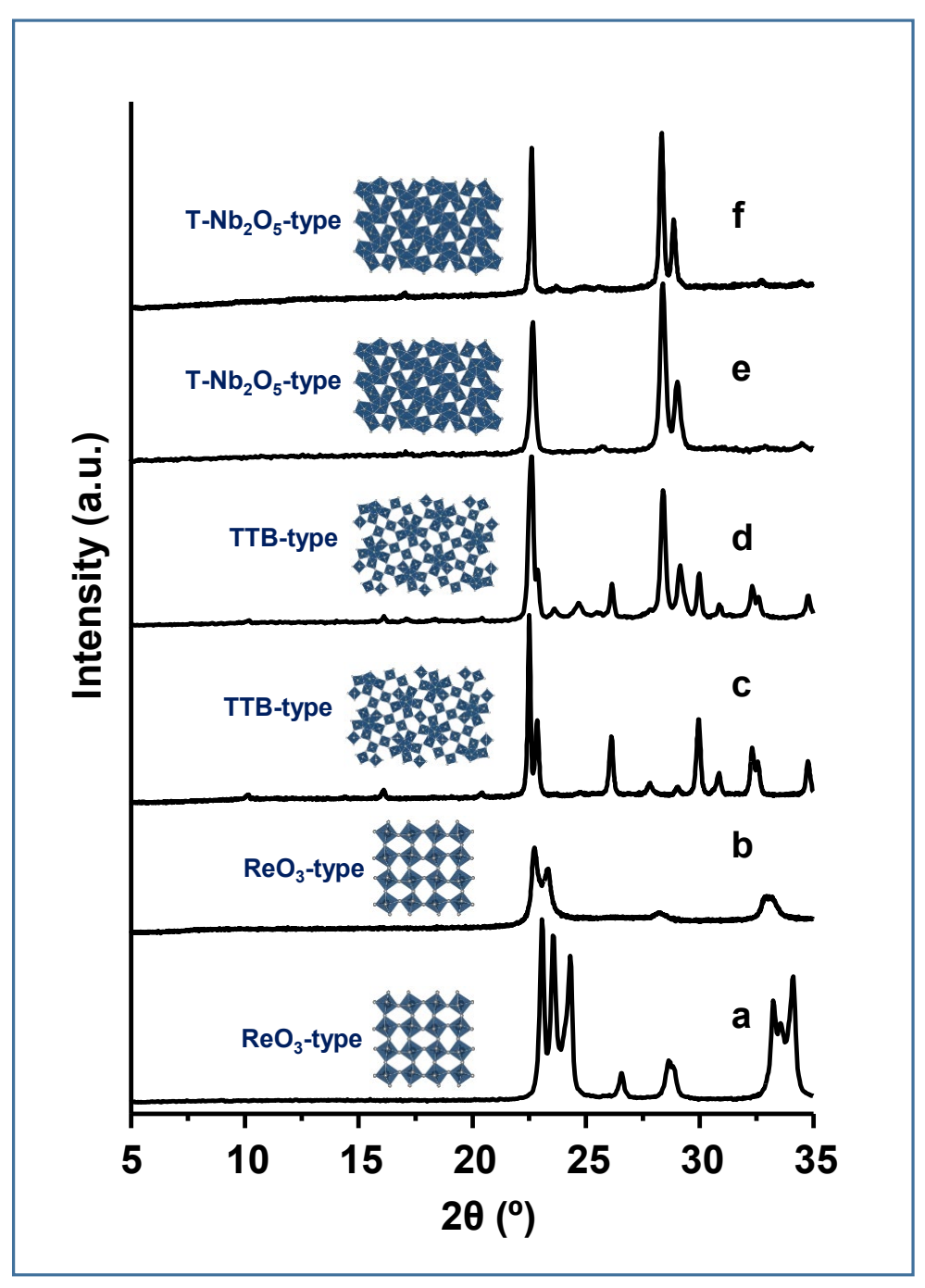

Fig. 2 

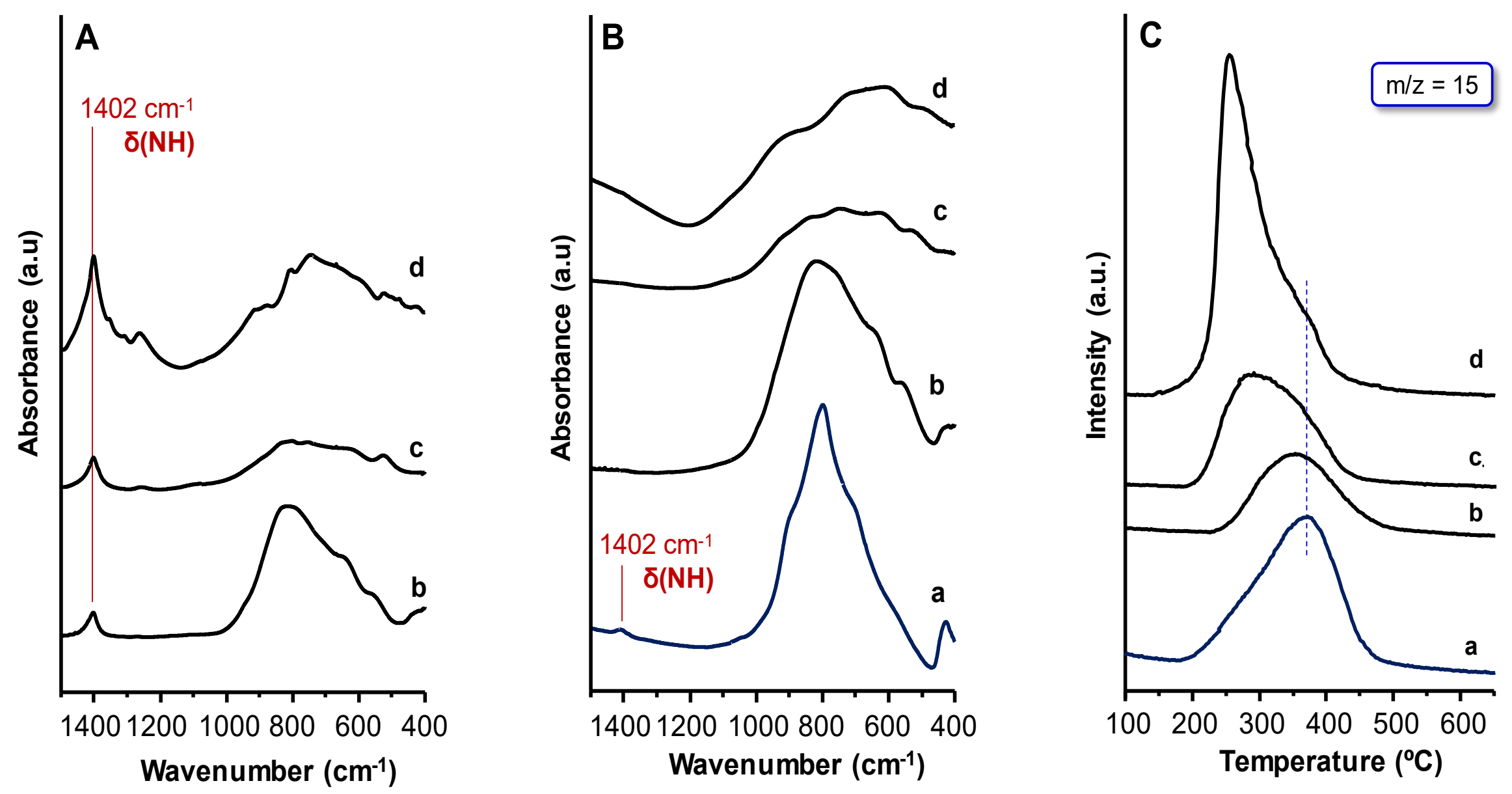

Figure 3 


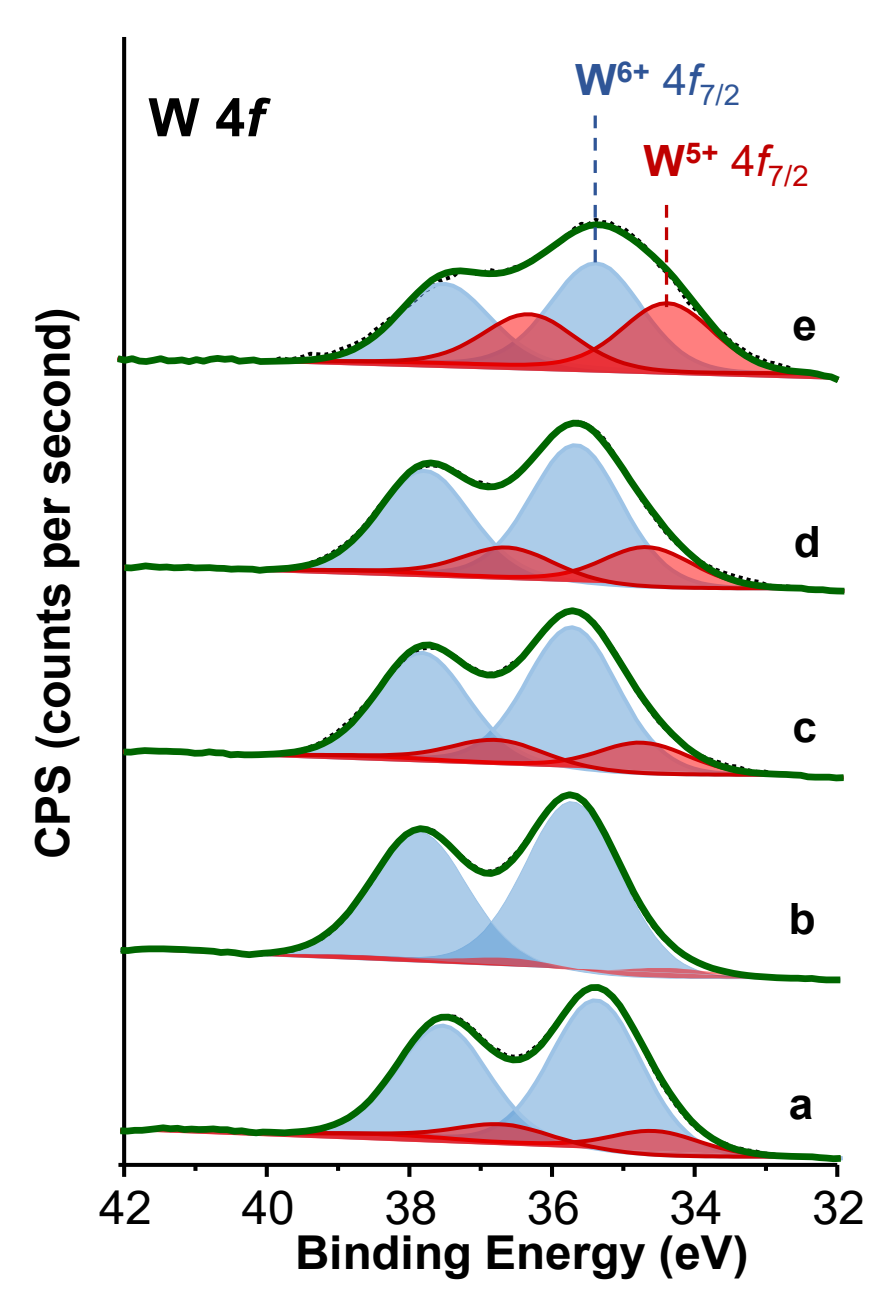

Fig. 4

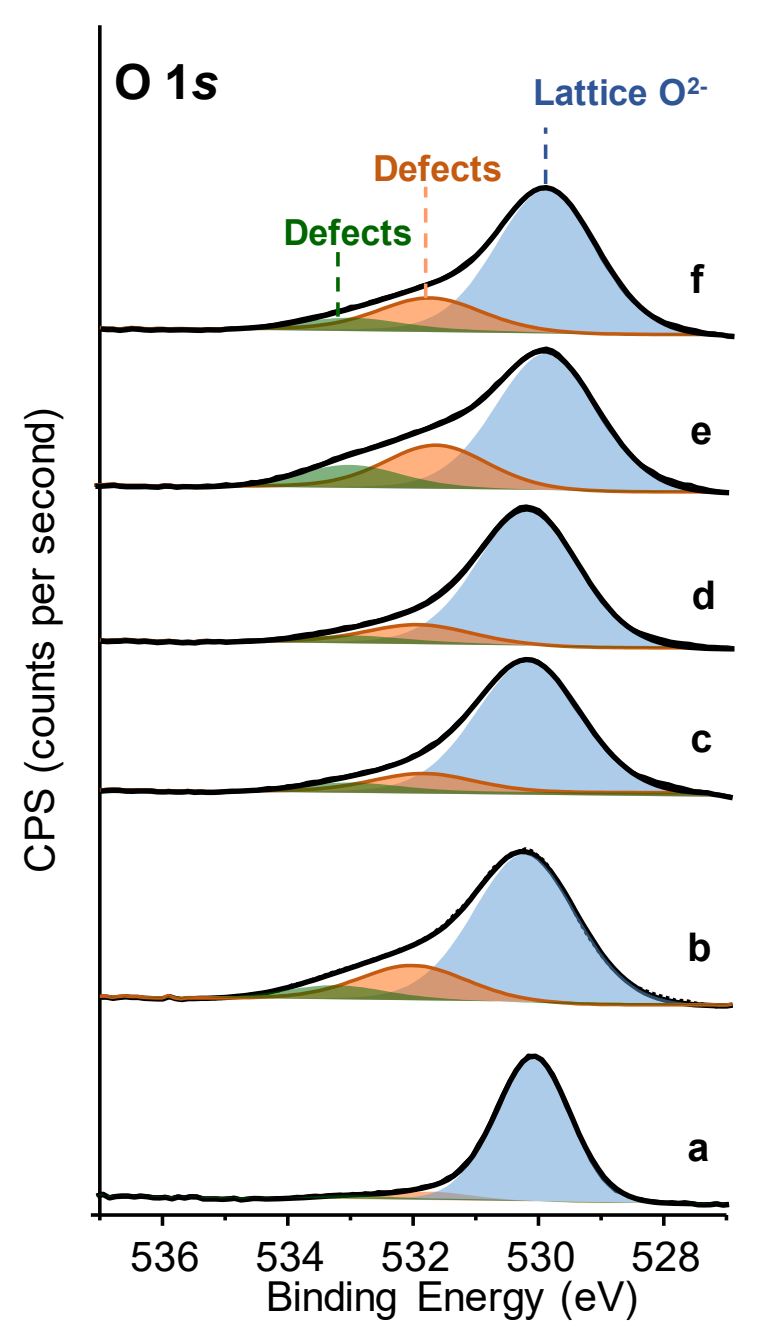

Fig. 5 

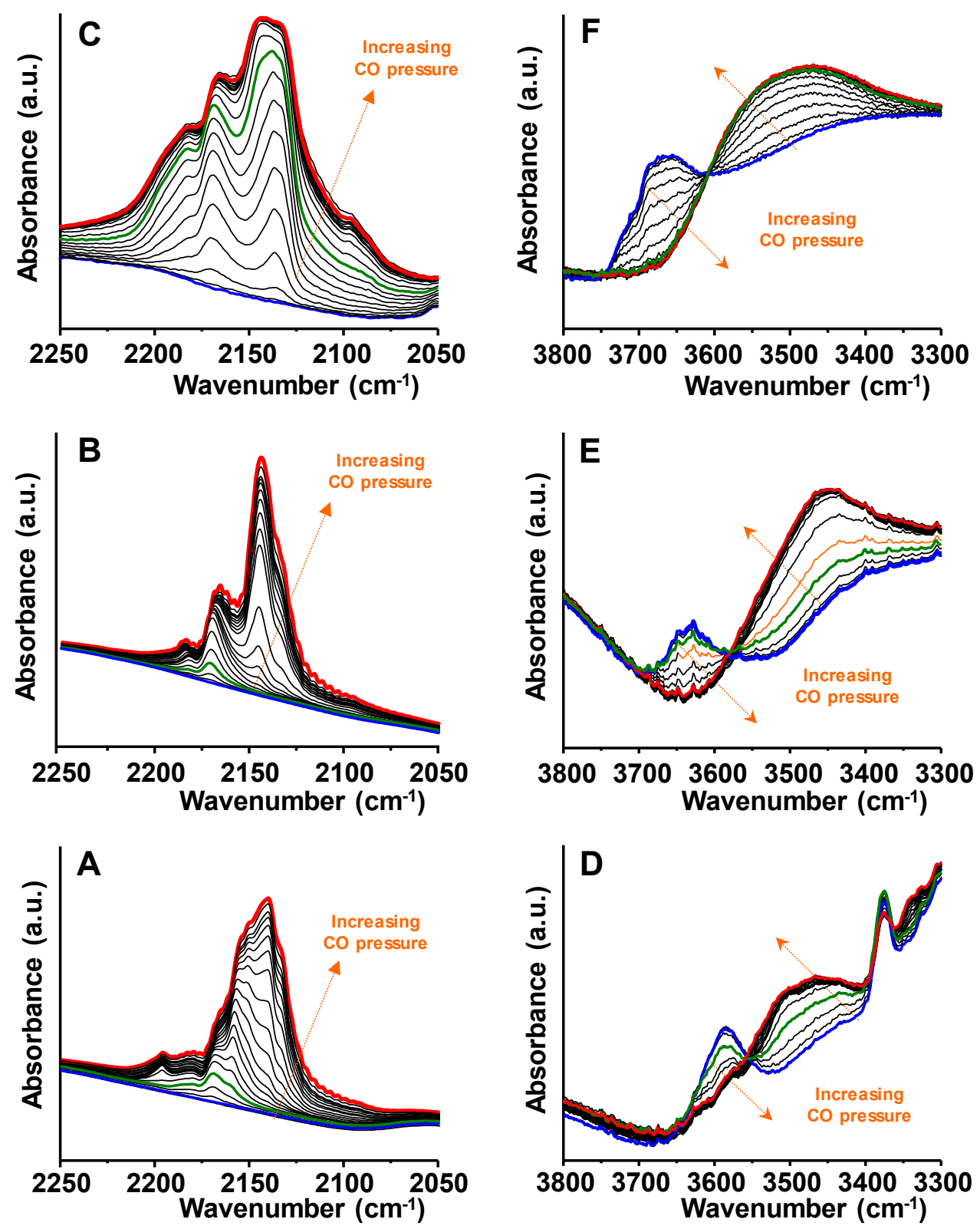

Fig. 6 

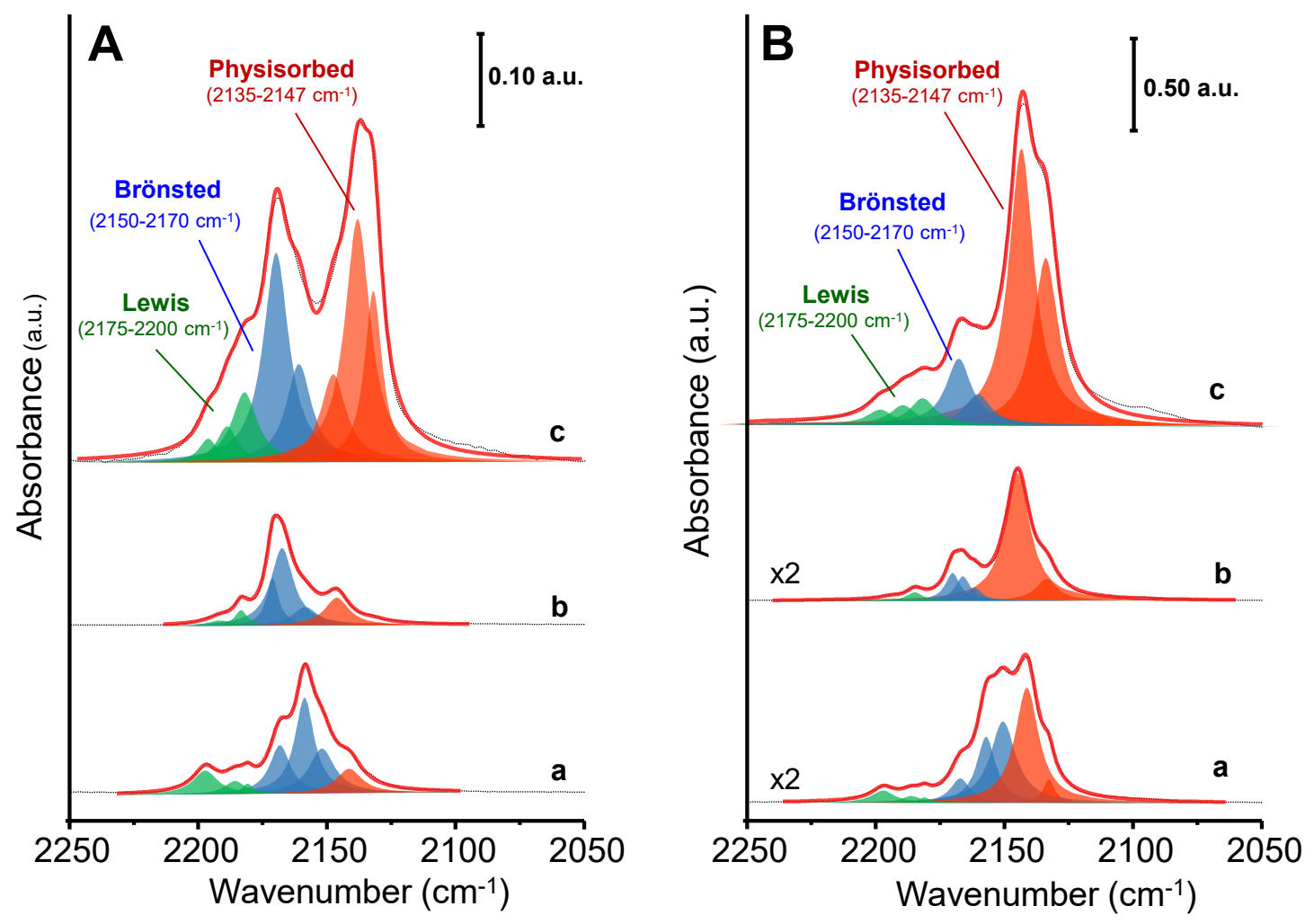

Fig. 7 

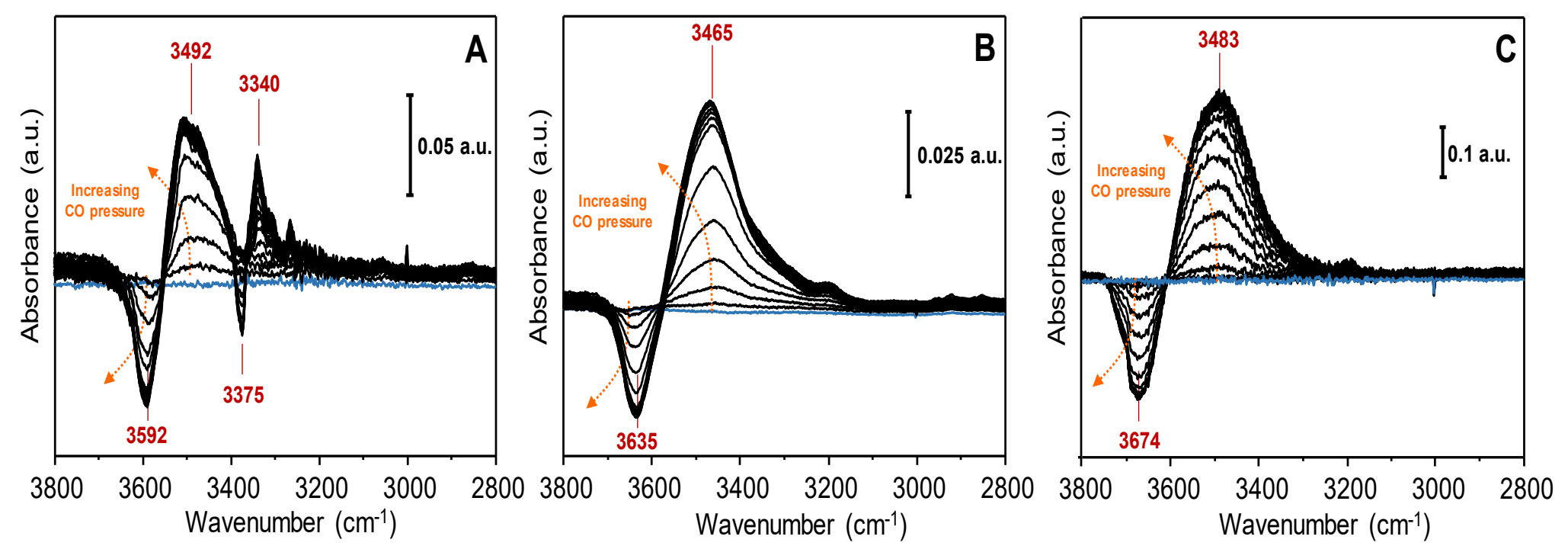

Fig. 8 

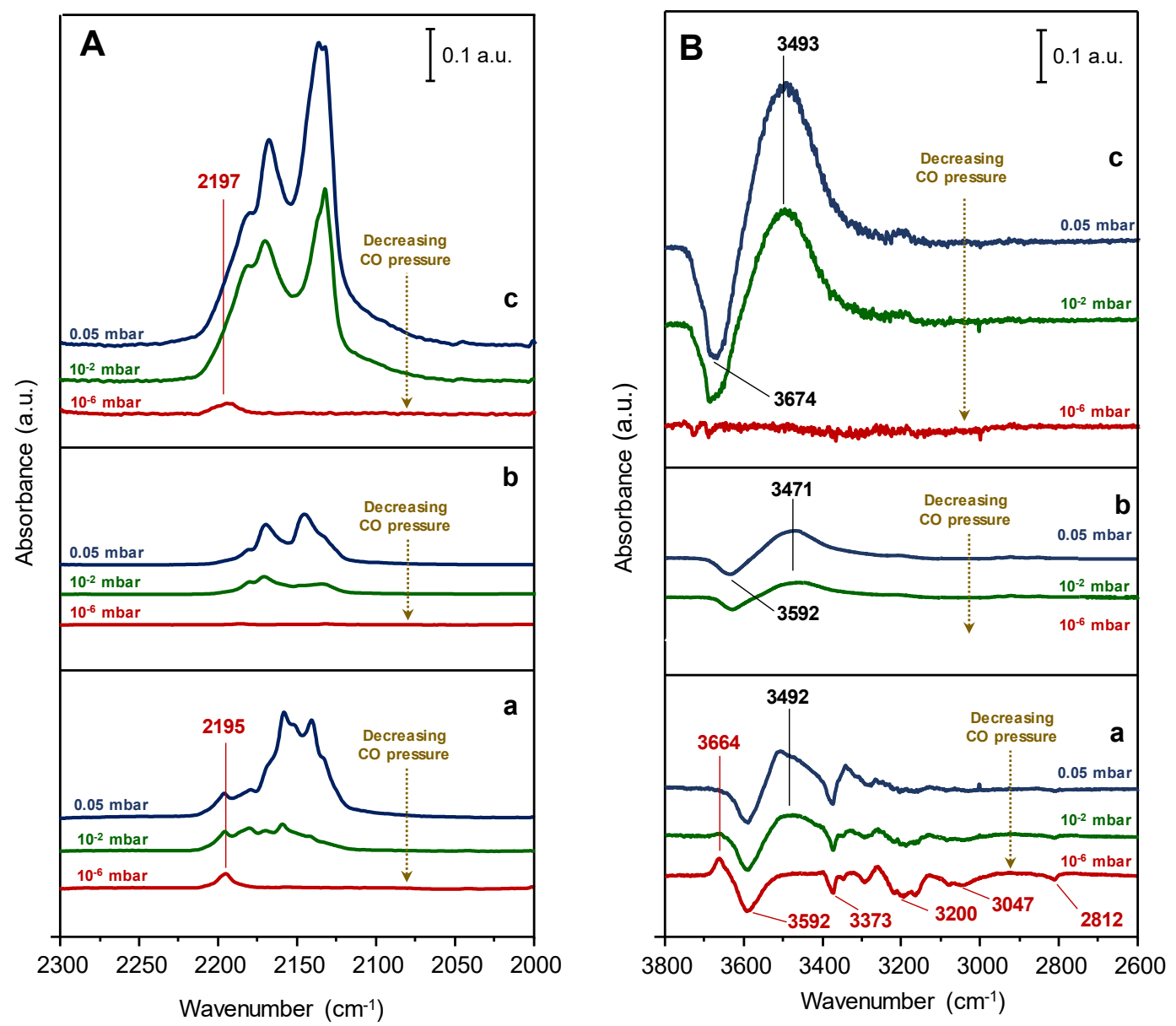

Fig. 9 


\section{Tungsten-Nio}

\section{bium Oxide Bronzes: A Bulk and Surface Structural Study}

Daniel Delgado ${ }^{a, b,},{ }^{*}$ Patricia Concepción ${ }^{a}$, Annette Trunschke ${ }^{b}$ and José M.

López Nietoa,"

Table of contents

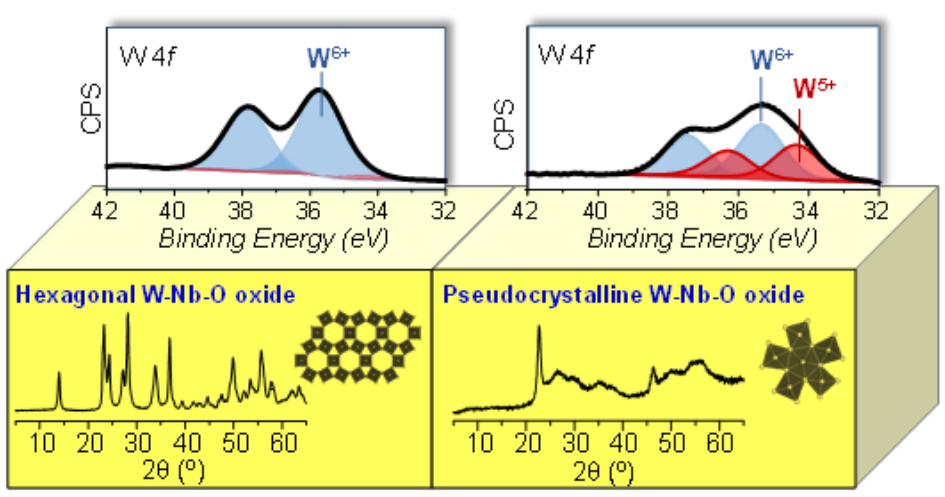

The physico-chemical and catalytic properties in glycerol dehydration of $\mathrm{W}-\mathrm{Nb}-\mathrm{O}$ mixed oxide bronzes, heat-treated at $550^{\circ} \mathrm{C}$, strongly depends on $\mathrm{Nb}$-content. 